\title{
Clubionidae from Laos and Thailand (Arachnida: Araneae)
}

\author{
PETER JÄGER ${ }^{1} \&$ PAKAWIN DANKITTIPAKUL ${ }^{2}$ \\ ${ }^{1}$ Arachnology, Research Institute Senckenberg, Senckenberganlage 25, D-60325 Frankfurt am Main, Germany; \\ peter.jaeger@senckenberg.de, corresponding author \\ ${ }^{2}$ Department of Biology, Faculty of Science, Chiang Mai University, Chiang Mai 50200, Thailand; pakawin@gmail.com
}

\begin{abstract}
Clubionidae collected in Laos and Thailand were investigated. Seven new species are described: Clubiona kai spec. nov. (male: Laos, Luang Prabang Prov.), Clubiona lala spec. nov. (female: Laos, Luang Nam Tha Prov.), Clubiona maipai spec. nov. (male: Thailand, Mae Hong Son Prov.), Clubiona kuu spec. nov. (male: Laos, Luang Prabang Prov.), Clubiona vukomi spec. nov. (male: Laos, Luang Nam Tha Prov.), Malamatidia zu spec. nov. (male: Laos, Luang Prabang Prov.) and Malamatidia christae spec. nov. (female: Laos, Luang Nam Tha Prov.). The genus Malamatidia, previously known from Sumatra, Sarawak, the Malaysian peninsular, Kalimantan, and Sulawesi is recorded from Laos (Luang Nam Tha Province) as northernmost distribution locality and is re-diagnosed. Cheiracanthium insulanum (Thorell, 1878), Cheiracanthium unicum Bösenberg and Strand, 1906, Clubiona abnormis Dankittipakul, 2008, Clubiona filicata O. Pickard-Cambridge, 1874, Clubiona melanothele Thorell, 1895 are recorded for the first time from Laos. Cheiracanthium insulanum, Clubiona abnormis, and Clubiona melanothele are additionally illustrated. A map with all records is provided.
\end{abstract}

Key words: Taxonomy, first descriptions, first records, sac spiders, Southeast Asia, Greater Mekong region

\section{Introduction}

Southeast Asian spiders received more attention after Deeleman-Reinhold (2001) and Murphy and Murphy (2000) published comprehensive books on spiders from this region. However, from recent collecting in Laos and Thailand between 2003 and 2010 it seems that most of the diversity is still unknown. Laos and Thailand belong to the IndoBurmesian Hotspot (Carr \& Langhammer 2010) and harbour a far higher diversity than known today. This becomes apparent when considering recent publications and descriptions of new taxa (e.g., Dankittipakul \& Singtripop 2008a, b; Jäger 2007; Jäger \& Praxaysombath 2009).

Clubionidae are abundant in subtropical and tropical habitats, especially in the foliage of shrubs and trees. Deeleman-Reinhold (2001) gave a thorough analysis on the Clubionidae from Southeast Asia, including a key to subfamilies. Further publications consulted are by Biswas and Raychaudhuri (1996) from Bangladesh, by Dankittipakul and Singtripop (2008a, b) from Thailand, by Ono (2009) from Vietnam, by Chen and Huang (2004) and Zhang and Yin (1999) from Taiwan and China, respectively, and by Chrysanthus (1967) from New Guinea. A synopsis of Japanese species was recently published by Ono and Hayashi (2009).

The present paper describes seven new species from the Greater Mekong region and lists new records of Clubionidae collected in Laos and Thailand.

\section{Material and Methods}

Spiders were preserved in $70 \%$ denatured ethanol. Female copulatory organs were dissected and observed in $96 \%$ lactic acid, if appropriate, i.e. if membranous structures were not affected by this procedure. Numbers within localities (Lxx) refer to numbering in Jäger (2007: L1-L36) and Jäger and Praxaysombath (2009: L37-L78; submitted: L79-L103).

Spination of legs is given in two different styles: in palps three digits refer to prolateral, dorsal and retrolateral spines, no matter in which position, four digits add in the last position number of ventral spines. Leg spines of the 
prolateral, dorsal, retrolateral and ventral side of each leg segment are noted separately and three positions are distinguished: proximal, medial, and distal. In some cases spines cannot unambiguously be assigned to one position. Some stronger bristles on dorsal patellae (d101) may be counted as thin spines in other publications (e.g., Deeleman-Reinhold 2001). These are not listed in the spination pattern in the descriptions below. A schematic course of the internal duct system is explained by the following symbols: open circle-copulatory orifice, $\mathrm{T}$-glandular appendages, arrow - fertilisation duct in direction of the uterus externus.

Abbreviations:

ALE—anterior lateral eyes

AME—anterior median eyes

AW - anterior width of dorsal shield of prosoma

d-dorsal

OL_opisthosoma length

OW-opisthosoma width

$\mathrm{p}$-prolateral

PL—prosoma length

PLE- posterior lateral eyes

PME-posterior median eyes

PW_-prosoma width

$\mathrm{r}$-retrolateral

RTA—retrolateral tibial apophysis

$\mathrm{v}$-ventral

I-IV/XII-legs I-IV / months I-XII

Museum collections:

SMF-Senckenberg Research Institute, Frankfurt, Germany (P. Jäger)

MHNG-Museum d'histoire naturelle, Genève, Switzerland (P. Schwendinger)

NHM—Natural History Museum, London, United Kingdom (J. Beccaloni)

\section{Results}

\section{Clubionidae Wagner, 1887}

\section{Cheiracanthium C.L. Koch, 1839}

The genus is placed by some colleagues in the family Miturgidae Simon, 1886 (see note and references in Platnick 2010). Here we follow Deeleman-Reinhold (2001) and Raven (2009, and references therein) in placing the Eutichurinae with Cheiracanthium in the Clubionidae.

\section{Cheiracanthium insulanum (Thorell, 1878)}

Figs 1-3, 71

Material examined. LAOS: Luang Nam Tha Province: 1 female, $5 \mathrm{~km} \mathrm{~N}$ of Luang Nam Tha, N 21 ${ }^{\circ} 1.201^{\prime}$, E $101^{\circ} 24.632 ', 587 \mathrm{~m}$ altitude, secondary forest, vegetation, at night, by hand, 7 November 2004, P. Jäger \& V. Vedel leg. (SMF 60277, L5). Champasak Province: 1 male, Pakse, Ban Ke, dry vegetation, at night, by hand, 27 November 2009, P. Jäger \& S. Bayer leg. (SMF 60316, L98).

The specimens were identified according to illustrations in Deeleman-Reinhold (2001) and Chen and Huang (2004). The male conductor of the present specimen is wider than that shown in Deeleman-Reinhold (2001), and more similar to that of Chen and Huang (2004). Deeleman-Reinhold (2001) illustrated apparently a female epigyne with mating plug, which is also present in the female from Luang Nam Tha (L5). Copulatory openings are easily 
visible after removing the plug. Variation in shape and course of the internal duct system led to the description of several synonymies by Barrion and Litsinger (1995). Therefore the epigyne and vulva is illustrated here as one example from Laos (Figs 1-3).

First record for Laos (Fig. 71: 1, 8).
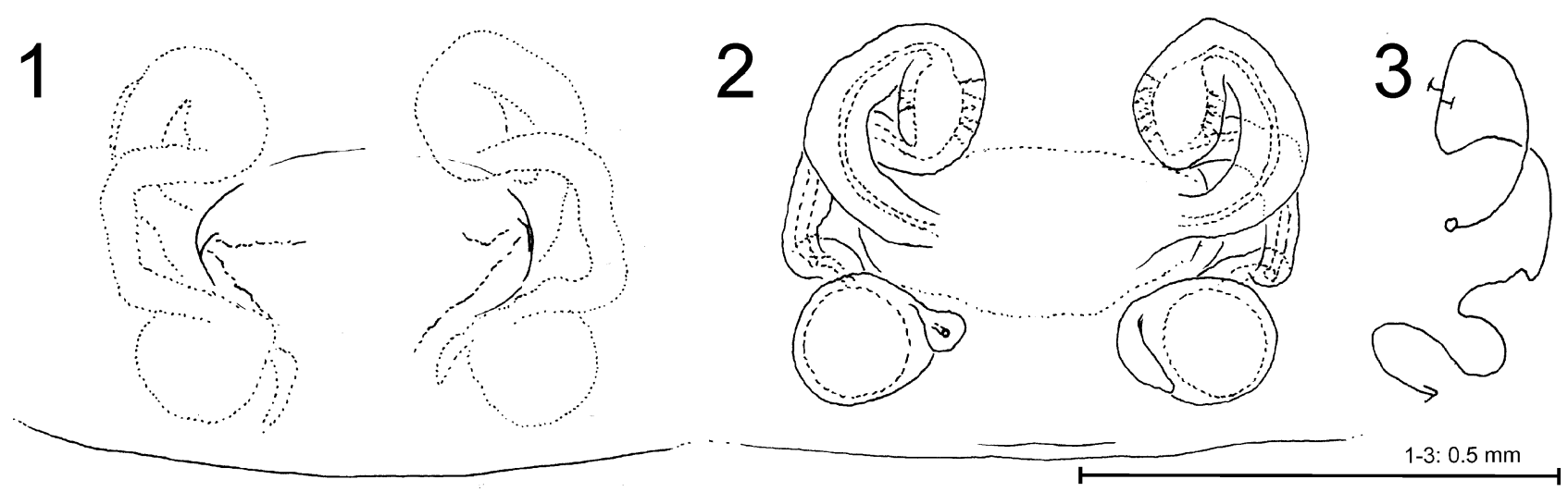

FIGURES 1-3. Cheiracantium insulanum (Thorell, 1878), female from Laos, Luang Nam Tha Province. 1 Epigyne, ventral. 2 Vulva, dorsal. 3 Schematic course of internal duct system, dorsal.

\section{Cheiracanthium unicum Bösenberg \& Strand, 1906}

Fig. 71

Material examined. LAOS: Oudomxai Province: 1 male, Oudomxai, stupa hill, N 2041'13.1”, E 101'59'13.1”, $638 \mathrm{~m}$ altitude, vegetation, at night and by day, by hand, 1 March 2008, P. Jäger leg. (SMF 60329, L54).

Additional material examined for comparison. Holotype male, JAPAN: Saga, W. Dönitz leg. (SMF 4495). Identified according to Ono (2009) and direct comparison with the holotype male. The present male is smaller (PL $1.7 \mathrm{~mm}$ ) than the holotype (PS length $2.5 \mathrm{~mm}$ ), but no differences between the palps could be recognised.

First record for Laos (Fig. 71:3).

\section{Clubiona Latreille, 1804}

This genus consists currently of more than 460 species (Platnick 2010). Deeleman-Reinhold (2001) proposed several species groups within the genus. She did not follow Mikhailov (1995) in using subgenera, but adopted his intrageneric grouping, which is used here, too.

\section{corticalis species-group}

\section{Clubiona kai spec. nov.}

Figs 4-12, 71

Type material: Holotype: male, LAOS: Luang Prabang Province: SE Luang Prabang, Nam Khan, Ban Keng Koung, 372 m altitude, N $19^{\circ} 40.963$ ', E $102^{\circ} 18.442$ ', along stream, disturbed forest, cultivated land, by hand, at night, 23 February 2008, P. Jäger leg. (SMF, L15).

Etymology. The species name is derived from the Lao word "kai", meaning "egg", referring to the egg-shaped tegulum; term in apposition.

Diagnosis. Small sized Clubioninae with body length of males $3.8 \mathrm{~mm}$, belonging to the corticalis speciesgroup. Male palp (Figs 4-7) similar to that of Clubiona didentata Zhang and Yin, 1998 described from Southern China, Yunnan. Males can be distinguished by 1) embolus with transversal branch clearly visible in ventral view (Fig. 5; hidden in $C$. didentata), 2) distal tegular tooth pointing prolatero-distally (Fig. 5; pointing distally in $C$. didentata), 3) RTA distinctly wider than long in retrolateral view (Fig. 6; slightly longer than wide in $C$. didentata). 


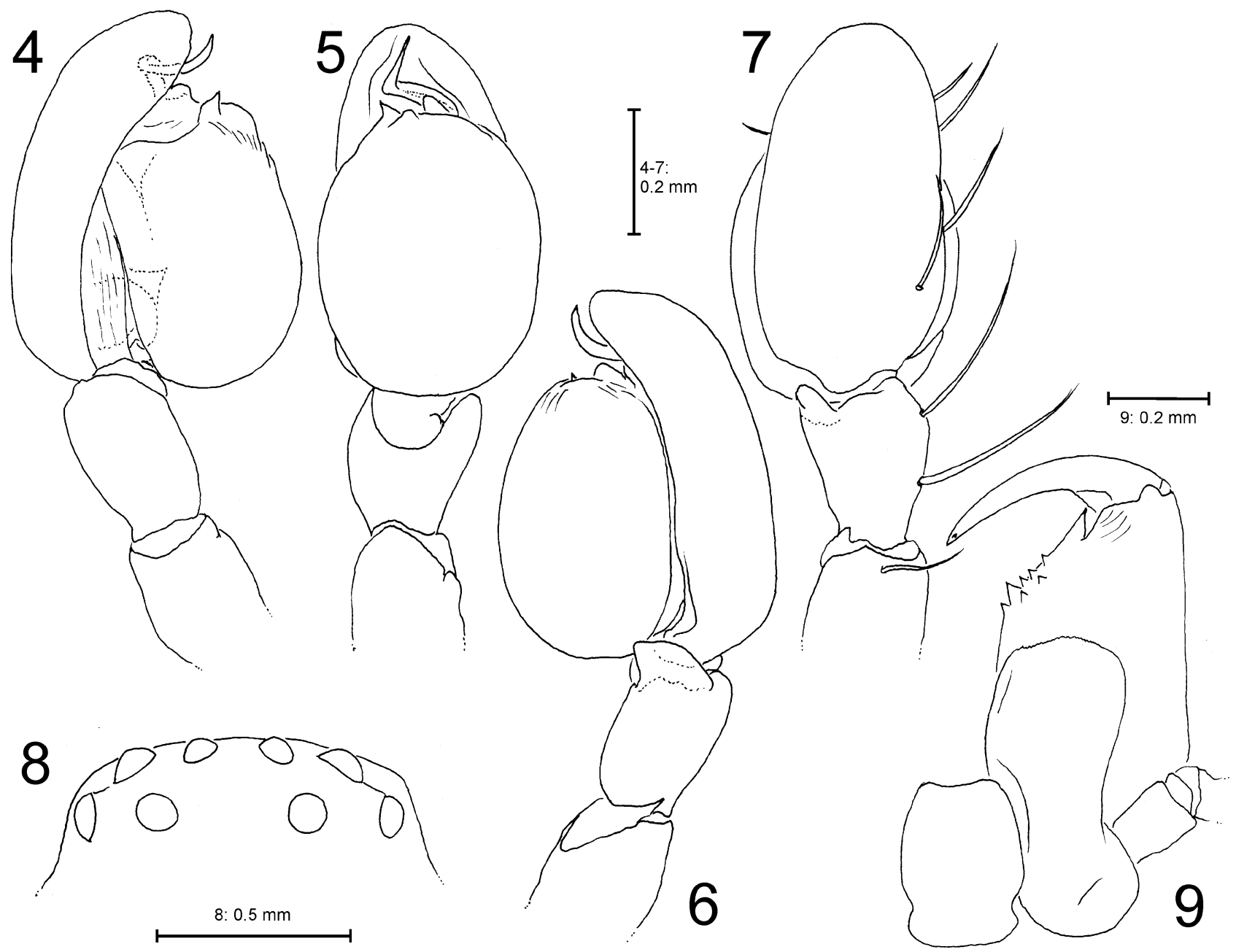

FIGURES 4-9. Clubiona kai spec. nov., holotype male from Laos, Luang Prabang Province, Ban Keng Koung. 4-7 Left palp (4 prolateral, 5 ventral, 6 retrolateral, 7 dorsal). 8 Eye arrangement, dorsal. 9 Labium, left chelicera and gnathocoxa, ventral.

Description. Male (holotype): PL 1.7, PW 125, AW 0.9, OL 2.1, OW 1.0. Eye diametres (Fig. 8): AME 0.10, ALE 0.13, PME 0.12, PLE 0.12. Eye interdistances: AME-AME 0.10, AME-ALE 0.07, PME-PME 0.29, PMEPLE 0.12, AME-PME 0.12, ALE-PLE 0.05, clypeus AME 0.05, clypeus ALE 0.05. Leg and pedipalp measurements: pedipalp $1.58(0.55,0.26,0.24,-, 0.53)$; leg I 3.95 (1.10, 0.60, 1.13, 0.72, 0.40); leg II 4.53 (1.27, 0.64, 1.35, 0.85, 0.42); leg III 3.79 (1.05, 0.52, 0.84, 0.95, 0.43); leg IV 4.92 (1.16, 0.57, 1.24, 1.40, 0.55). Leg formula. 4213. Spination: Pedipalp femur: 020, patella 020, tibia 2000, tarsus 3002; Femur I p001, d111, II-IV p001, d111, r001; Patella IV r010; Tibia I-II v220, III p010, r010, v010, IV p011, r011, v010; Metatarsus I-II v200, III p101, r101, v203, IV p111, r111, v103.

Chelicerae with distinct frontal bulge (Fig. 12), cheliceral furrow with 5 anterior and 2 posterior teeth in continuous rows (Fig. 9). Tarsi and metatarsi with sparse to absent scopulae. Tarsi I-II with reduced claw tufts. Spinnerets and anal tubercle elongated.

Palp as in diagnosis. Cymbium distinctly longer than tibia. Subtegulum visible in prolateral view. RTA slightly pointed at ventral side. Tegulum ovoid extending prolaterally and retrolaterally beyond cymbium. Embolus arising distally from tegulum, with basal torsion and distal sickle-shaped bend (Figs 4-7).

Colour in ethanol (Figs 10-12). Yellowish brown without colour pattern. Dorsal prosoma darker brown anteriorly, fovea distinct. Chelicerae, gnathocoxae and labium reddish brown. Sternum marginally more strongly sclerotised, darker anteriorly. Appendages pale yellow with leg joints slightly darker. Dorsal opisthosoma pale yellowish brown with oval light brown patch (resembling a scutum), reaching posterior half; ventral opisthosoma with epiandrium as triangular pale white zone bordered by darker patches. Posterior spinnerets dark.

Female: unknown.

Distribution. Known only from the type locality (Fig. 71: 5). 

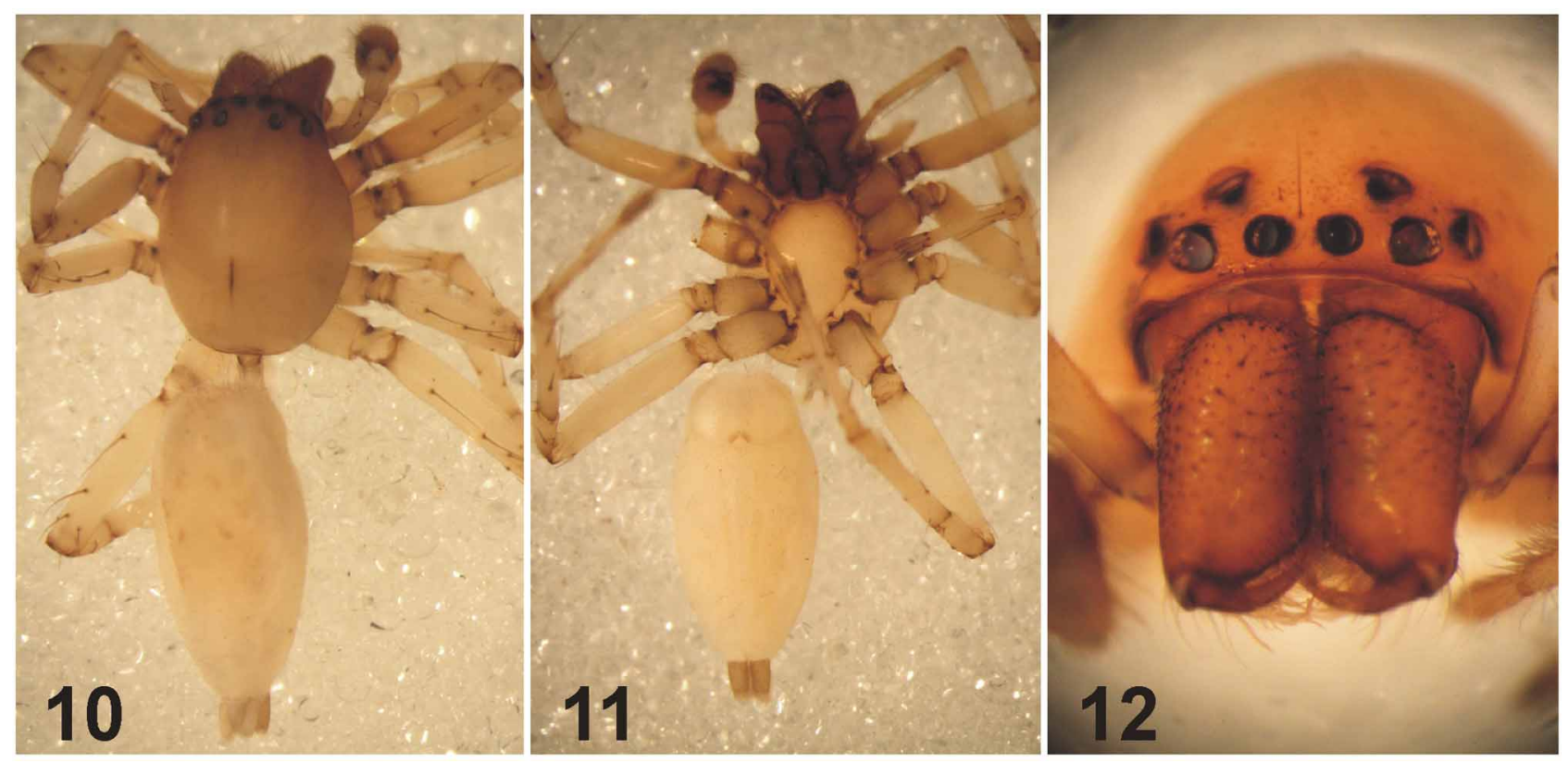

FIGURES 10-12. Clubiona kai spec. nov., holotype male from Laos, Luang Prabang Province, Ban Keng Koung, habitus (10 dorsal, 11 ventral; opisthosoma detached; 12 frontal).

\section{japonica species-group}

\section{Clubiona vukomi spec. nov.}

Figs 13-21, 71

Type material: Holotype: male, LAOS: Luang Nam Tha Province: $2-3 \mathrm{~km} \mathrm{~N}$ of Luang Nam Tha, $597 \mathrm{~m}$ altitude, N 2101.201', E 101 ${ }^{\circ} 24.632^{\prime}$, slope, trees, under stones, by hand, at night, 2 March 2008, P. Jäger leg. (SMF, L42).

Paratypes: THAILAND: Chiang Mai Province and district: 1 male, Chiang Mai city, $330 \mathrm{~m}$ altitude, in flower, P.J. Schwendinger leg. (MHNG). Chai Ya Phum Province: 1 male, Pa Hin Ngam Nationa Park, dipterocarp forest, $450 \mathrm{~m}$ altitude, 15 October 2009, P. Dankittipakul leg. (MHNG).

Etymology. The species name is derived from the Ndebele term "vimbani ukuzalisana okungela mikhawulo", meaning "stop overpopulation" and referring to the human overpopulation threatening natural habitats of spiders. Ndebele is a language from South Africa, belonging to the Nguni group of Bantu languages. It is used here to emphasize the global relevance of overpopulation; term in apposition.

Diagnosis. Small sized Clubioninae with a body length of $6.0 \mathrm{~mm}$ (Figs 19-20), belonging to the japonica species-group (Deeleman-Reinhold 2001; Mikhailov 1995). Males can be recognised by the dorsally situated RTA, the strong sclerotised tegular apophysis and the shape of the filiform embolus with a semicircular tip in a plain transversal to the basal part of the embolus (Figs 13-16).

Note. Although there are superficial similarities especially in the opisthosomal pattern between this new species and the female of $C$. melanothele from Lak Sao, both are considered different species due to slight but clear differences in the colouration: $C$. vukomi spec. nov. exhibits pale chelicerae with an indistinct pattern (Fig. 21; dark reddish-brown in C. melanothele, Fig. 34), the dorsal shield has a marbled pattern extending to fovea with a median line between eyes reaching almost to fovea (Fig. 19; extending to half distance between eyes and fovea and without median line in C. melanothele, Fig. 34). 


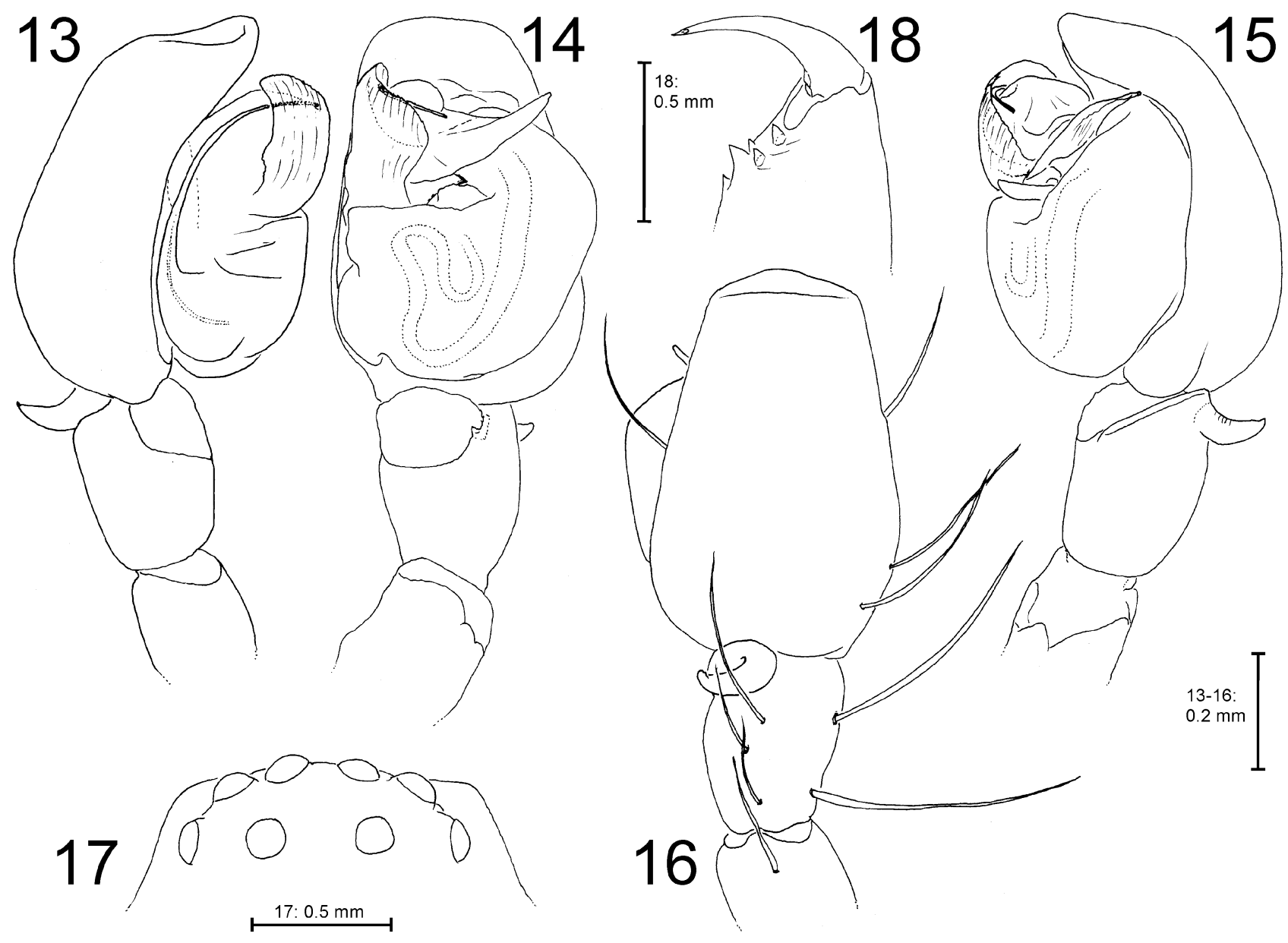

FIGURES 13-18. Clubiona vukomi spec. nov., holotype male from Laos, Luang Nam Tha Province. 13-16 Right palp, mirrored (13 prolateral, 14 ventral, 15 retrolateral, 16 dorsal). 17 Eye arrangement, dorsal. 18 Left chelicera, ventral.

Description. Male (holotype): PL 2.7, PW 2.0, AW 1.1, OL 3.3, OW 1.7. Eye diametres (Fig. 17): AME 0.15, ALE 0.16, PME 0.13, PLE 0.14. Eye interdistances: AME-AME 0.09, AME-ALE 0.04, PME-PME 0.23, PMEPLE 0.16, AME-PME 0.15, ALE-PLE 0.09, clypeus AME 0.06, clypeus ALE 0.06. Leg and pedipalp measurements: pedipalp $2.16(0.76,0.30,0.38,-, 0.72)$; leg I 7.0 (2.0, 0.95, 1.95, 1.35, 0.75); leg II 7.5 (2.1, 1.05, 2.1, 1.5, 0.75); leg III 6.1 (1.8, 0.85, 1.35, 1.5, 0.6); leg IV 9.35 (2.6, 1.05, 2.4, 2.6, 0.7). Leg formula. 4213. Spination: Pedipalp femur: 030, patella 010, tibia 2300, tarsus 1002; Femur I p001, d111, r01(0)0, II p001, d111, III p001, d111, r001, IV p001, d111, r001; Patella IV r010; Tibia I v221, II p001, v221, III p011, r011, v111, IV p011, r011, v111; Metatarsus I-II v200, III p111, d010, r101, v203, IV p111, d010, r111, v213.

Chelicerae without frontal bulge (Fig. 21), cheliceral furrow with 3 anterior (median largest) and 2 posterior teeth (Fig. 18). Tarsi and metatarsi I-II with scopulae, distal tibiae I-II with two rows of single scopula hairs ventrally. Spinnerets and anal tubercle elongated.

Palp as in diagnosis. Cymbium distinctly longer than tibia, blunt and with dorsal depression distally. RTA short, massive, hook-like bent, connected to a retrolateral sclerotised distal ridge. Tegulum extending beyond cymbium retrolaterally in ventral view. Sperm duct running a double U-turn in the centre of tegulum. Embolus arising from prolateral side of tegulum, basal part sickle-shaped. Membranous conductor arising prolaterally, covering the distal coil of embolus. Tegular apophysis pointed, reaching cymbial margin in ventral view (Figs 13-16).

Colour in ethanol (Figs 19-21). Pale yellow with distinct colour pattern. Dorsal prosoma with head region marbled and eyes region darker. Chelicerae with longitudinal bands and inner parts dark. Opisthosoma grey, dorsally with distinct pattern consisting of broad stripes and blotches. Spinnerets and anal tubercle dark.

Female: unknown.

Distribution. Known from Laos, Luang Nam Tha (type locality) and Thailand, Chiang Mai and Chai Ya Phum Provinces (Fig. 71: 1, 11-12). 

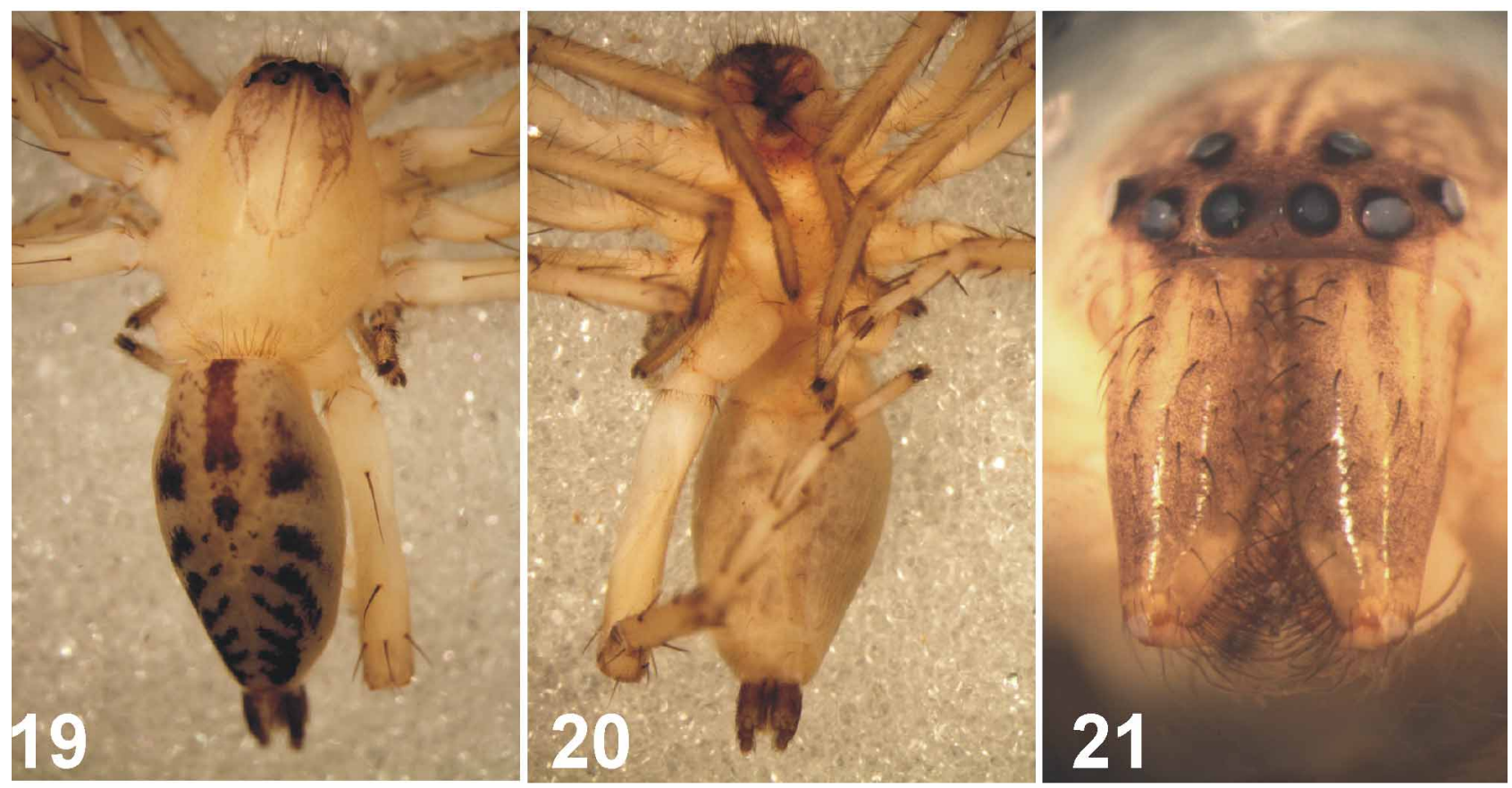

FIGURES 19-21. Clubiona vukomi spec. nov., holotype male from Laos, Luang Nam Tha Province, habitus (19 dorsal, 20 ventral, 21 frontal).

\section{Clubiona lala spec. nov.}

Figs 22-25, 28-30, 71

Type material: Holotype: Female, LAOS: Luang Nam Tha Province: 6 air km N of Luang Nam Tha, $589 \mathrm{~m}$ altitude, N $21^{\circ} 03^{\prime} 32.10^{\prime \prime}$, E $101^{\circ} 24^{\prime} 3.0^{\prime \prime}$, vegetation close to stream, water-duct under street, by day, by hand, 7 March 2008, P. Jäger leg. (SMF, L41).

Etymology. The species name is an abbreviation and derived from the Lao term "lăai làak", meaning "diverse", referring to the diversity of the japonica-group in Southeast Asia; term in apposition.

Diagnosis. Small sized Clubioninae with a body length of $7.0 \mathrm{~mm}$ in females and strong opisthosomal and leg pattern (Figs 28-29), belonging to the japonica species-group. Females can be distinguished from those of $C$. campylacantha Dankittipakul, 2008, C. octoginta Dankittipakul, 2008, and C. suthepica Dankittipakul, 2008 by 1) having its epigynal atrium more rectangular (Fig. 22), 2) entire internal duct system being situated behind atrium (Fig. 23), 3) head of spermathecae of internal duct system laterad (Fig. 23).

Description. Female (holotype). PL 2.8, PW 1.9, AW 1.3, OL 4.2, OW 2.0. Eye diametres (Fig. 25): AME 0.14, ALE 0.16, PME 0.15, PLE 0.16. Eye interdistances: AME-AME 0.11, AME-ALE 0.07, PME-PME 0.29, PME-PLE 0.18, AME-PME 0.14, ALE-PLE 0.08, clypeus AME 0.07, clypeus ALE 0.06. Leg and pedipalp measurements: pedipalp $2.51(0.86,0.38,0.51,-, 0.76)$; leg I $6.8(1.9,1.0,1.8,1.2,0.9)$; leg II 7.7 (2.1, 1.05, 2.1, 1.5, 0.95); leg III 5.95 (1.7, 0.7, 1.3, 1.55, 0.7); leg IV 8.4 (2.3, 1.0, 2.0, 2.4, 0.7). Leg formula. 4213. Spination: Pedipalp: femur 030, patella 020, tibia 2101, tarsus 1014; Femur I-II p001, d111, III p011, d111, r011, IV p001, d111, r001; Patella III-IV r010; Tibia I-II v220, III p011, r011, v120, IV p011, r011, v110; Metatarsus II v100, III p111, d010, r111, v204, IV p111, d010, r111, v114.

Clypeus with sclerotised margin (Fig. 30). Chelicerae with only weakly developed frontal bulge (Fig. 30), cheliceral furrow with 3 anterior and 2 posterior teeth (Fig. 24). Tarsi and metatarsi I-II with sparse scopulae, III-IV with scopulae almost absent. Tibiae I-II with two indistinct ventral bands of scopula hairs. Spinnerets and anal tubercle elongated.

Copulatory organ as in diagnosis. Epigyne with two long slit sense organs lateral of atrium. Posterior margin of atrium only very slightly rebordered. Atrium separated from epigastric furrow by more than one length of atrium. Membranous bursae with small projections on surface. Spermathecae compact, spermathecal bases short, not extending laterally beyond duct system (Figs 22-23). 

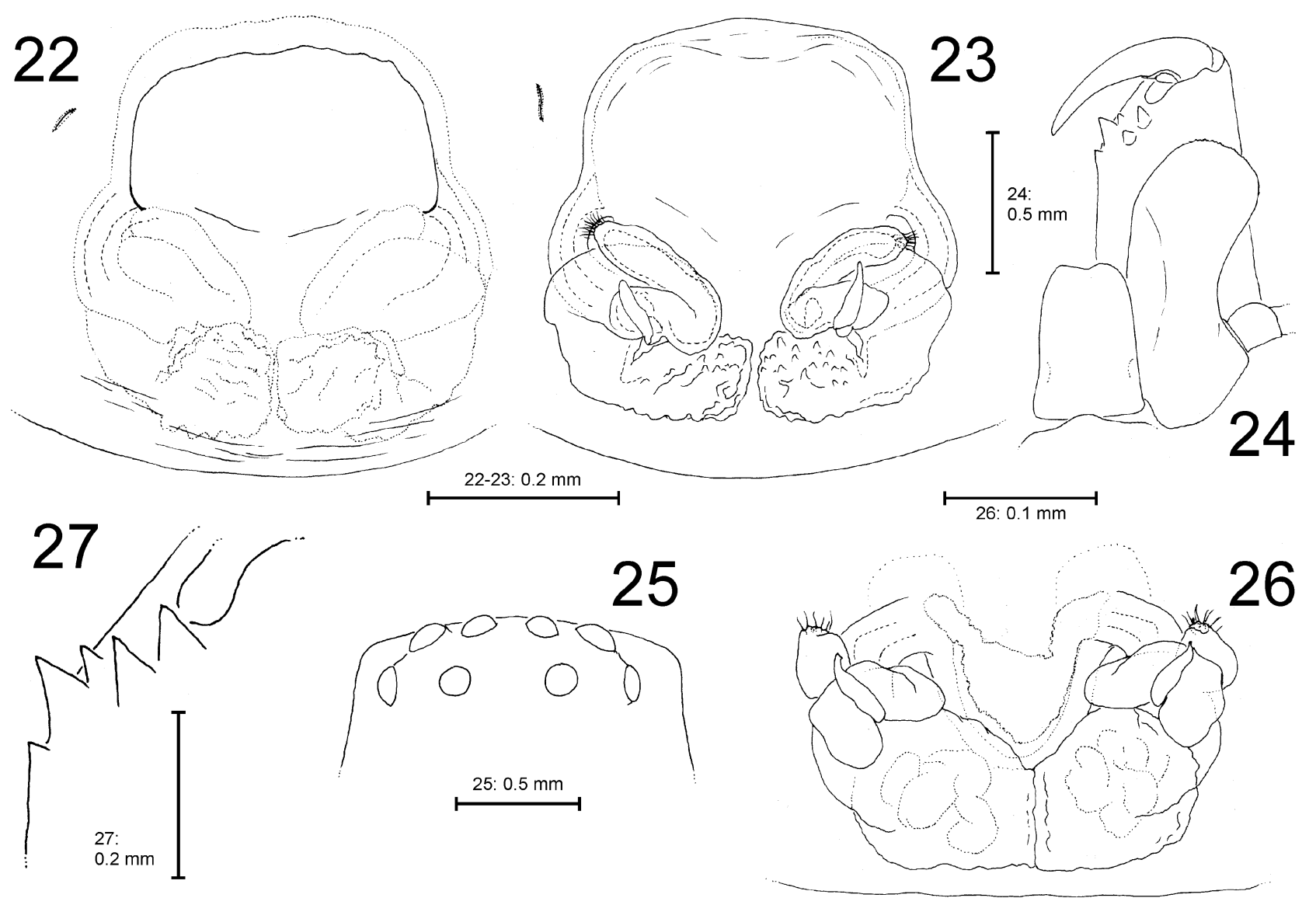

FIGURES 22-27. 22-25 Clubiona lala spec. nov., holotype female from Laos, Luang Nam Tha Province. 26 Clubiona melanothele Thorell, 1895, female from Bolikhamsay Province, Lak Sao. 27 Clubiona abnormis Dankittipakul, 2008, female from Champasak Province, That Fane. 22 Epigyne, ventral. 23, 26 Vulva, dorsal. 24 Labium, left chelicera and gnathocoxa, ventral. 25 Eye arrangement, dorsal. 27 Left cheliceral furrow, ventral.

Colour in ethanol (Figs 28-30). Yellowish to reddish brown with distinct dark colour pattern. Dorsal prosoma with marginal bands and marbled pattern in head region and on frontal chelicerae, the latter reddish brown. Sternum with margin darker. Legs with distinct dark patches. Opisthosoma grey with distinct dark pattern. Dorsal opisthosoma with patches and stripes, in anterior half with band above heart, in posterior half with chevrons, the latter discontinuous. Ventral opisthosoma with broad median band mottled with black. Lateral spinnerets and anal tubercle dark.

Male: unknown.

Distribution. Known only from the type locality (Fig. 71: 1).

\section{Clubiona filicata O. Pickard-Cambridge, 1874}

Fig. 71

Material examined. LAOS: Vientiane Province: 1 male, 10 air km N Vang Vieng, Ban Phoxay, N 190.731', E $102^{\circ} 26.766^{\prime}, 260 \mathrm{~m}$ altitude, shrubs, small trees, by day and night, by hand, 17 November 2004, P. Jäger \& V. Vedel leg. (SMF 60278, L18).

The male was identified according to illustrations of Dankittipakul and Singtripop (2008a). The male copulatory organ was in accordance with the illustrations except for the embolus tip which was not freely visible but hidden behind the distal embolus coil.

First record for Laos (Fig. 71: 6). 

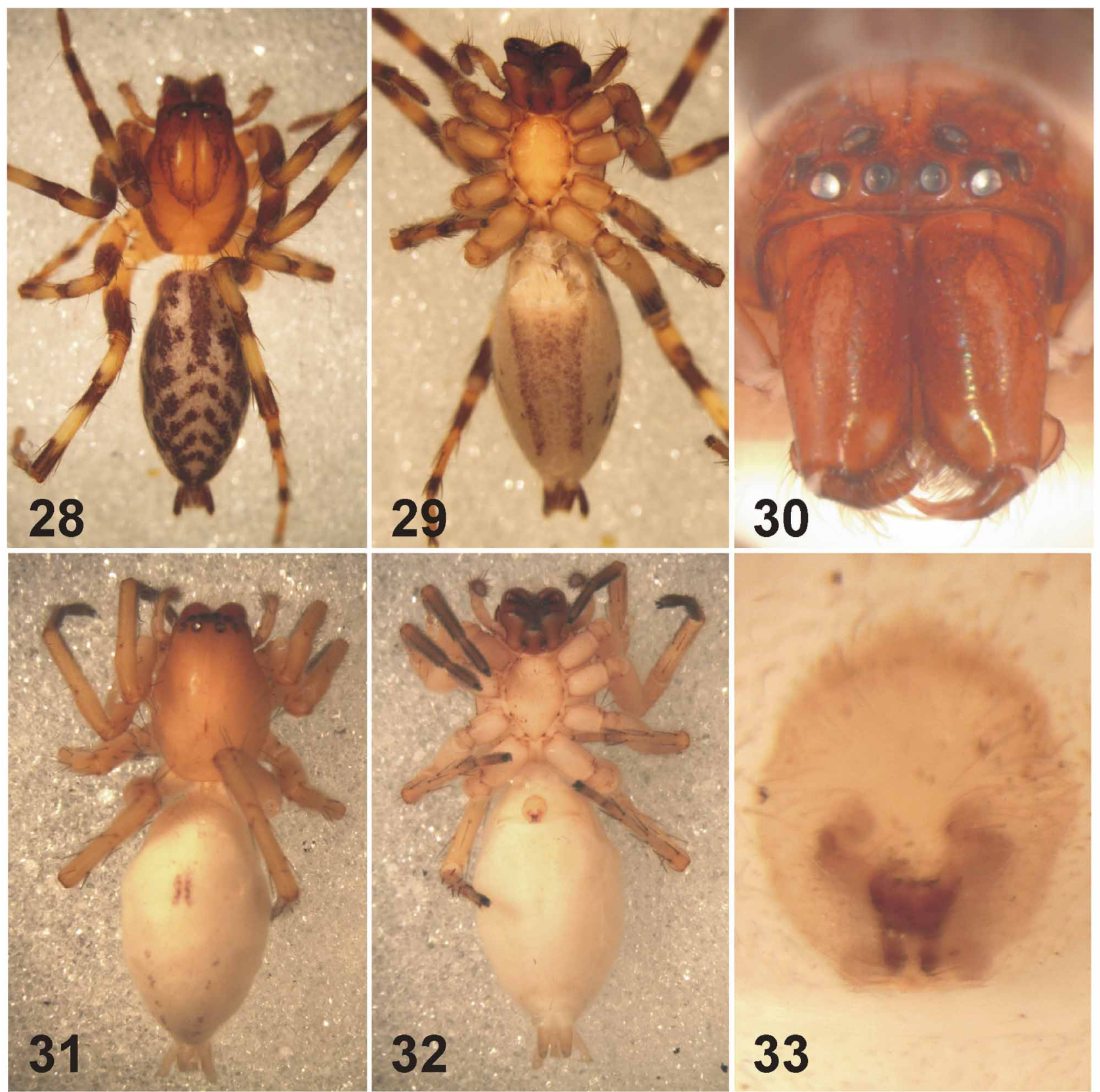

FIGURES 28-33. 28-30 Clubiona lala spec. nov., holotype female from Laos, Luang Nam Tha Province. 31-33 Clubiona abnormis Dankittipakul, 2008 from Champasak Province, That Fane. 28-32 Habitus (28, 31 dorsal, 29, 32 ventral, 30 frontal). 33 Epigyne, not cleared, ventral.

\section{Clubiona melanothele Thorell, 1895}

Figs 26, 34-36, 71

Material examined. LAOS: Bolikhamsay Province: 1 female, Lak Sao, shrubs, at night, by hand, 2 March 2010, P. Jäger \& J. Martens leg. (SMF 60280, L90).

Material examined for comparison. 1 female syntype of C. melanothele, BURMA: Tharrawaddy, Oates leg., 1895/217 (NHM 1895.9.21.75-6).

Gravely (1931: fig. 16 B) and Deeleman-Reinhold (2001: figs 53-54) illustrated the female epigyne, the latter author included additionally a dorsal view of the vulva, but without the membranous posterior bursae (see Fig. 26) shown for a group of related species in Dankittipakul and Singtripop (2008a: C. suthepica, fig. 60; C. octoginta, fig. 47; C. campylacantha, fig. 40). Characteristic for C. melanothele are the two dark sclerotised circular areas around the copulatory openings and the V-shaped structure in the centre of the epigyne (Figs 35-36). The three spe- 
cies from Thailand, listed above, do not show any of these characteristics, but a distinct anterior margin. Whether or not this species is a junior synoym of $C$. melanosticta Thorell, 1890, as supposed by Deeleman-Reinhold (2001) and mentioned in Dankittipakul and Singtripop (2008a) remains questionable. According to a comparison of illustrations in Zhang and Yin (1998: figs 1-5), Deeleman-Reinhold (2001: figs 51-54) and Dankittipakul and Singtripop (2008a: fig. 52-54), a species apparently close to C. melanothele and C. melanosticta is $C$. cirrulata Zhang and Yin, 1998 from China (Yunnan: Mengla). Another specimen probably belonging to this species-group is the female paratype of $C$. transversa Zhang \& Yin, 1998 (Zhang \& Yin 1998: figs 16-17) (see also note under C. kuu spec. nov.).

First record for Laos (Fig. 71: 7).
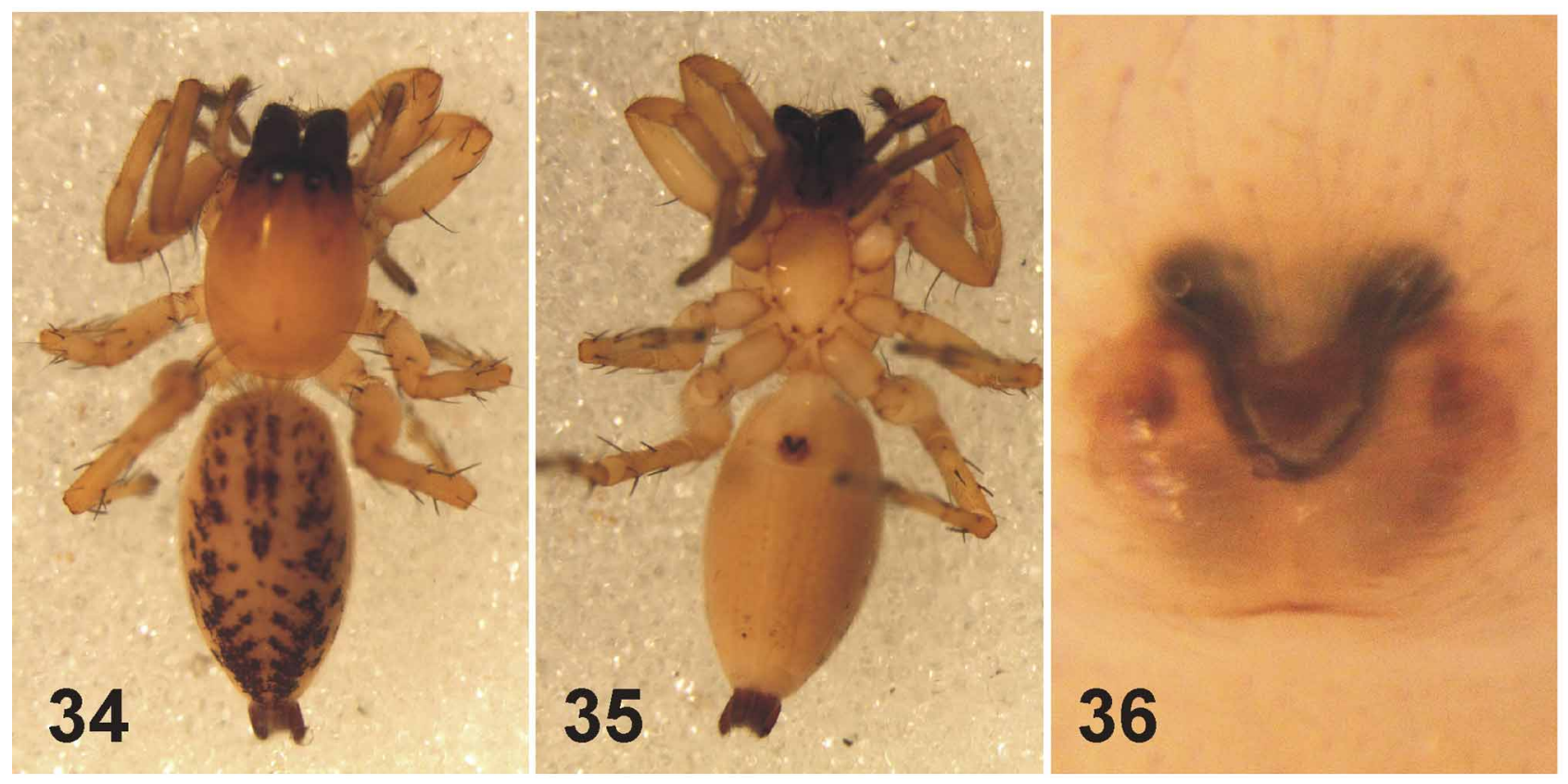

FIGURES 34-36. Clubiona melanothele Thorell, 1895, female from Bolikhamsay Province, Lak Sao. 34-35 Habitus (34 dorsal, 35 ventral). 36 Epigyne, not cleared, ventral.

\section{Clubiona abnormis Dankittipakul, 2008}

Figs 27, 31-33, 71

Material examined. LAOS: Champasak Province: 1 female, E of Pakse, Bolaven Plateau, Ban Lak 38, That

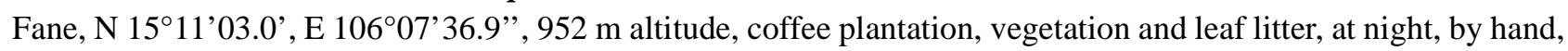
19 March 2010, P. Jäger \& J. Martens leg. (SMF, L95).

Note. The species was described from Thailand (Nakhorn Ratchasima Province: Khao Yai National Park) by Dankittipakul (in Dankittipakul \& Sintripop 2008a). The placement in the japonica-group was uncertain due to the characters of copulatory organs. Generally, characters of the present female are congruent with those illustrated in the original description. The only differences are a paler pattern on dorsal opisthosoma (Fig. 31) and a kidneyshaped dilated terminal portion of spermathecal heads (Fig. 33; ovoid in figs 66-67 of Dankittipakul \& Singtripop 2008a). Despite these differences the female is considered as belonging to C. abnormis. In the original description no spination pattern was provided, this is added below.

Redescription. PL 2.75, OL 4.3. Spination: Pedipalp femur: 130, patella 020, tibia 2110, tarsus 1115; Femur I-II p001, d111, III-IV p001, d111, r001; Patella IV r010; Tibia I-II v220, III p110, r110, v110, IV p110, r110, v111; Metatarsus I-II v200, III p111, d010, r011, v204, IV p111, d010, r111, v214. Chelicerae with 3 anterior and 2 posterior teeth (Fig. 27). Scopulae on tarsi and metatarsi I-II distinct, in III-IV sparse. Tibiae I-II with two ventral rows of scopula hairs. Tarsi I-II with slightly reduced claw tufts. Opisthosomal colour pattern reduced especially in posterior half of opisthosoma (Fig. 31).

First record for Laos (Fig. 71: 9). 


\section{hystrix species-group}

\section{Clubiona maipai spec. nov.}

Figs 37-45, 52-56, 71

Type material: Holotype: male, THAILAND: Mae Hong Son Province: close to Ban Nam Rin, logged bamboo, by hand, 13 September 2003, D. Kovac leg. (SMF).

Paratypes: 8 males, 8 females, same locality as holotype, September 2003 (SMF), 1 male, 1 female, dito (MHNG).

Additional material examined for comparison. 1 male, 1 female paratype of Clubiona damirkovaci Deeleman-Reinhold, 2001, MALAYSIA: Malay peninsula, Gombak Research Station N of Kuala Lumpur, from bamboo internodes, 1 July 1991, Damir Kovac leg. (SMF 60487).

Etymology. The species name is derived from the Thai and Lao word "mâipai", meaning "bamboo", referring to the habitat where the type series was collected by the bamboo researcher Damir Kovac; term in apposition.

Diagnosis. Small sized Clubioninae with body length of males 4.9-6.1 mm (Figs 52-53) and of females 5.5$7.6 \mathrm{~mm}$ (Figs 54-55), belonging to the hystrix species-group. Closely related to Clubiona damirkovaci DeelemanReinhold, 2001 and $C$. kuu spec. nov. Males can be distinguished from both species by 1) the narrow and short base of RTA in retrolateral view (Fig. 38; narrow and long in C. damirkovaci, wide and short in C. kuu spec. nov.), 2) the small but distinct distal tegular hump (Fig. 37; indistinct in $C$. damirkovaci, developed more prominent in $C$. kuu spec. nov.), 3) number and arrangement of cheliceral teeth, namely 6 (5-7) anterior and 4 (3-5) posterior teeth in a straight row (Fig. 41; 5 anterior and 4 posterior teeth in a straight row in $C$. damirkovaci, 5 anterior and 3 posterior teeth with the two anterior and the distal posterior separated in $C$. kuu spec. nov.). Females can be distinguished from those of $C$. damirkovaci by the distinctly longer intromittent ducts (Figs 42-45), and from $C$. papuana Chrysanthus, 1967 by the presence of glandular appendages at ventral anterior spermathecae (Fig. 42; absent in C. papuana, Chrysanthus, 1967: figs 28-29) and by the fertilisation duct arising from anterior spermathecae (Fig. 43; arising from posterior spermathecae in C. papuana).

Description. Male (holotype). PL 2.6, PW 1.8, AW 1.1, OL 3.1, OW 1.3. Eye diametres (Fig. 40): AME 0.18, ALE 0.16, PME 0.16, PLE 0.18. Eye interdistances: AME-AME 0.07, AME-ALE 0.02, PME-PME 0.25, PMEPLE 0.13, AME-PME 0.09, ALE-PLE 0.04, clypeus AME 0.02, clypeus ALE 0.03. Leg and pedipalp measurements: pedipalp 2.14 (0.80, 0.33, 0.30, -, 0.71); leg I 5.85 (1.7, 0.9, 1.6, 1.15, 0.5); leg II 7.2 (2.1, 1.0, 2.15, 1.4, 0.55); leg III 5.55 (1.7, 9.65, 1.3, 1.4, 0.5); leg IV 8.1 (2.3, 0.85, 1.9, 2.35, 0.7). Leg formula. 4213. Spination: Pedipalp: femur 130, patella 020, tibia 2102, tarsus 1102; Femur I p011, d111, r011, II p011, d111, r001, III p011, d111, r011, IV p001, d111, r001; Patella IV r010; Tibia I-II v220, III p011, r011, v210, IV p102, r102, v203; Metatarsus I-II v200, III p011, r011, v120, IV p112, r112, v113.

Chelicerae with frontal bulge, cheliceral furrow with 6 anterior and 4 tiny posterior teeth (Fig. 41). Metatarsi and tibiae I-II with two scopulae bands ventrally. Tarsi I-II with reduced claw tufts. Spinnerets and anal tubercle elongated.

Palp as in diagnosis. Tibia diverging distally in retrolateral view. Cymbium distinctly longer than tibia, with less sclerotised ridge retrolatero-distally (probably functional conductor). Small part of subtegulum visible prolatero-proximally. Distal RTA thin and spine-like. Embolus arising prolatero-distally from tegulum, its basal part wide, narrowing to filiform tip. Sperm duct running an elongated loop (Figs 37-39).

Colour in ethanol (Figs 52-53). Pale yellowish brown without colour pattern, dorsal prosoma and chelicerae a bit darker, sternum marginally darker.

Female (paratype, SMF). PL 2.8, PW 2.1, AW 1.35, OL 3.5, OW 1.5. Eye diametres: AME 0.17, ALE 0.18, PME 0.17, PLE 0.15. Eye interdistances: AME-AME 0.10, AME-ALE 0.05, PME-PME 0.28, PME-PLE 0.15, AME-PME 0.11, ALE-PLE 0.07, clypeus AME 0.03, clypeus ALE 0.04. Leg and pedipalp measurements: pedipalp 2.31 (0.77, 0.37, 0.52, -, 0.65); leg I 6.0 (1.8, 0.9, 1.6, 1.15, 0.55); leg II 7.25 (2.1, 1.05, 2.1, 1.4, 0.6); leg III 5.8 (1.8, 0.7, 1.3, 1.4, 0.6); leg IV 8.55 (2.5, 0.7, 2.1, 2.45, 0.8). Leg formula. 4213. Spination: Pedipalp: femur 130, patella 010, tibia 2212, tarsus 1013; Femur I p011, d011, II p011, d111, III p011, d111, r001, IV p001, d111, r001; Patella 0; Tibia I-II v220, III p011, r011, v110, IV p011, r011, v110; Metatarsus I-II v200, III p111, r101, v203, IV p111, r111, v113. 

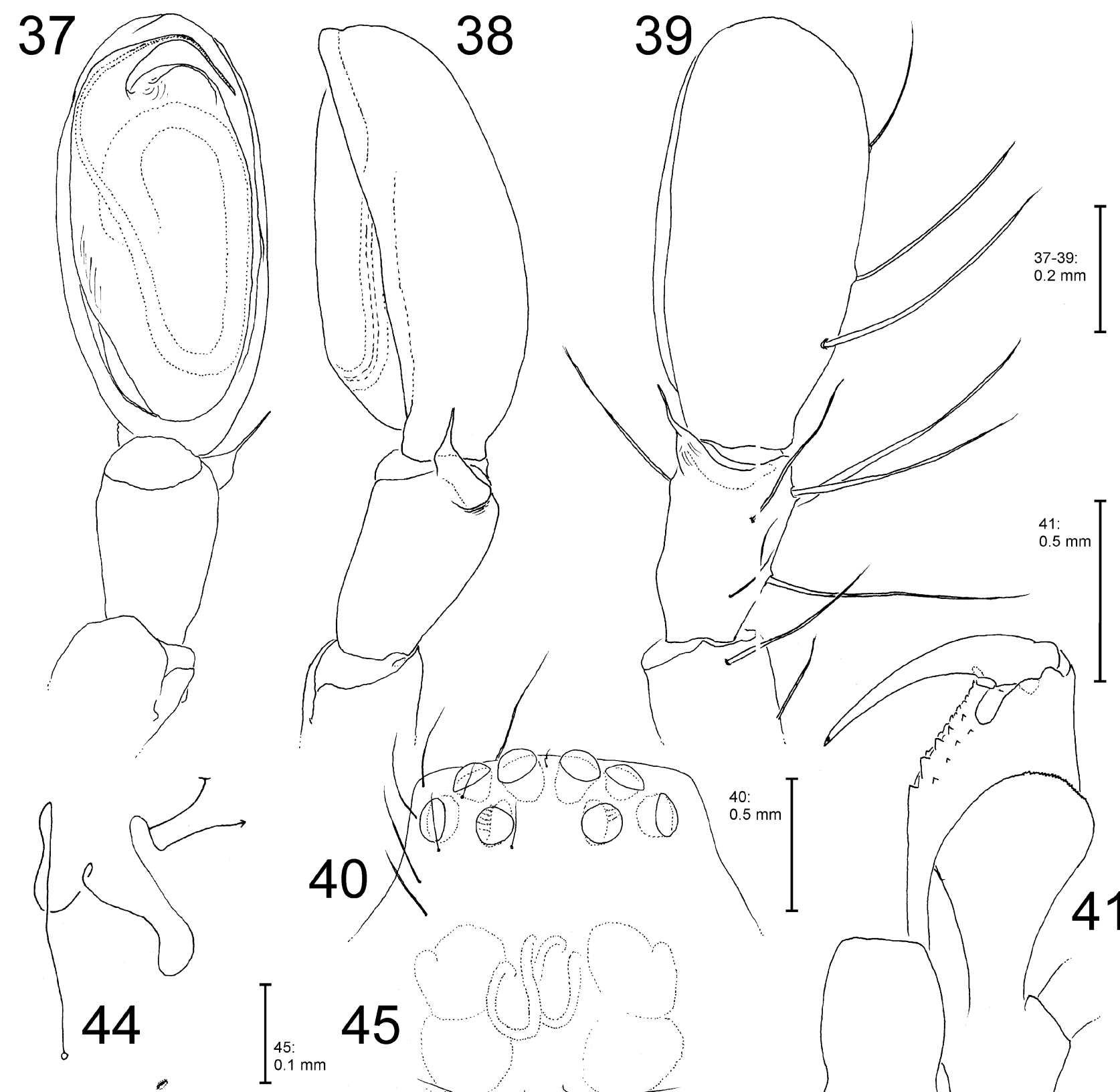
Spinnerets and anal tubercle elongated.

Copulatory organ as in diagnosis. Copulatory openings situated at two small transversal ridges in posterior epigyne. Posterior margin of epigyne medially only slightly bulged. One slit sense organ anterior of epigyne (Fig. 42). Intromittent ducts running from openings parallel and slightly converging, turning between anterior spermathecae at an angle of $180^{\circ}$ to the ventral side, coiling and being discharged into posterior spermathecae. Anterior spermathecae slightly smaller than posterior ones, antero-mediad. Fertilisation ducts antero-laterad (Fig. 43). Ushaped parts of intromittent ducts in ventral view varying in length (Figs 42, 45).

Colour in ethanol (Figs 54-55). As in male.

Distribution. Known only from the type locality (Fig. 71: 10).

\section{Clubiona kuu spec. nov.}

Figs 46-50, 57-60, 71-72

Type material: Holotype: male, LAOS: Luang Prabang Province: SE Luang Prabang, Nam Khan, Ban Keng Koung, 372 m altitude, N $19^{\circ} 40.963^{\prime}$, E $102^{\circ} 18.442^{\prime}$, along stream, disturbed forest, cultivated land, at tree bark, by hand, at night, 8 March 2006, P. Jäger \& J. Altmann leg. (SMF, L15).

Paratype: 1 male, LAOS: Luang Prabang Province: Nam Ou, Nong Khiao, Tham Pathok, $373 \mathrm{~m}$ altitude, N $20^{\circ} 33.082^{\prime}$, E $102^{\circ} 37.925^{\prime}$, in front of cave, bananas, trees, bushes, at night, by hand, 29 February 2008 , P. Jäger leg. (SMF, L7).

Additional material examined for comparison. 1 male, 1 female paratype of Clubiona damirkovaci Deeleman-Reinhold, 2001: MALAYSIA: Malay peninsula, Gombak Research Station N of Kuala Lumpur, from bamboo internodes, 1 July 1991, Damir Kovac leg. (SMF 60487).

Etymology. The species name is derived from the Lao word "kuu", meaning "to threaten", referring to the threatened habitats by the human overpopulation; term in apposition.

Diagnosis. Small sized Clubioninae with body length of males $4.3 \mathrm{~mm}$ (Figs 57-58), belonging to the hystrix species-group. Closely related to Clubiona damirkovaci Deeleman-Reinhold, 2001 and C. maipai spec. nov. Males can be distinguished by 1) smaller size, 2) the wide and short base of RTA in retrolateral view (Fig. 47; narrow and long in $C$. damirkovaci, narrow and short in $C$. maipai spec. nov.), 3) the prominent tegular hump (Fig. 46; indistinct in $C$. damirkovaci, distinct, but smaller in C. maipai spec. nov.), 4) number and arrangement of cheliceral teeth, namely 5 anterior and 3 posterior teeth with the distal two anterior and the distal posterior separated (Fig. 51; 5 anterior and 4 posterior teeth in a continuous, straight row in C. damirkovaci, 6 (5-7) anterior and 4 (3-5) posterior teeth in a continuous, straight row in C. maipai spec. nov.).

Note. The male of $C$. transversa Zhang and Yin, 1998 resembles that of $C$. kuu spec. nov. Shape of tegulum, embolus and distal tegular bulge including the course of the sperm duct show striking similarities with males of the hystrix species-group. However, the RTA lacks in the original description the fine distal part as shown for $C$. maipai spec. nov. and $C$. kuu spec. nov. This tiny tip can either have been overlooked, have been confused with a hair or bristle, or simply have been broken off. Apparently the female holotype of that species might be not conspecific with the male paratype, as it shows a completely different bauplan than females of other species of the hystrix species-group (see note under C. melanothele).

Description. Male (holotype). PL 2.0, PW 1.5, AW 0.9, OL 2.3, OW 1.4. Eye diametres (Figs 49-50): AME 0.13, ALE 0.14, PME 0.12, PLE 0.13. Eye interdistances: AME-AME 0.08, AME-ALE 0.02, PME-PME 0.22, PME-PLE 0.11, AME-PME 0.10, ALE-PLE 0.04, clypeus AME 0.04, clypeus ALE 0.03. Leg and pedipalp measurements: pedipalp $1.77(0.63,0.28,0.26,-, 0.60)$; leg I $4.25(1.2,0.7,1.1,0.8,0.45)$; leg II $4.6(1.3,0.75,1.25$, $0.85,0.45)$; leg III $4.0(1.1,0.6,0.85,0.95,0.5)$; leg IV $5.55(1.5,0.7,1.35,1.4,0.6)$. Leg formula. 4213 . Spination: Pedipalp femur: 130, patella 010, tibia 21(thin)01, tarsus 1002; Femur I p001, d111, r01(0)0, II p001, d111, III p001, d111, r001, IV p001, d111, r001; Patella IV r010; Tibia I-II v220, III p100, r100, v010, IV p110, r110, v110; Metatarsus II v100, III p111, r101, v203, IV p111, r101, v123.

Clypeus with sclerotised margin, chelicerae with distinct frontal bulge (Fig. 59), cheliceral furrow with 5 anterior and 3 smaller posterior teeth (Fig. 51). Tarsi and metatarsi with sparse scopulae, tibiae I-II with two bands of sparse scopulae ventrally. Tarsi I-II with reduced claw tufts. Spinnerets and anal tubercle elongated.

Palp as in diagnosis. Tibia diverging distally only slightly in retrolateral view. Cymbium distinctly longer than tibia, with less sclerotised ridge retrolatero-distally than in C. maipai spec. nov. (probably functional conductor). 
Small part of subtegulum visible prolatero-proximally. Distal RTA thin and spine-like. Embolus arising prolaterodistally from tegulum, its basal part wide, narrowing to filiform tip. Sperm duct running an elongated loop, extending proximally not as far as that from C. maipai spec. nov. (Figs 46-48).

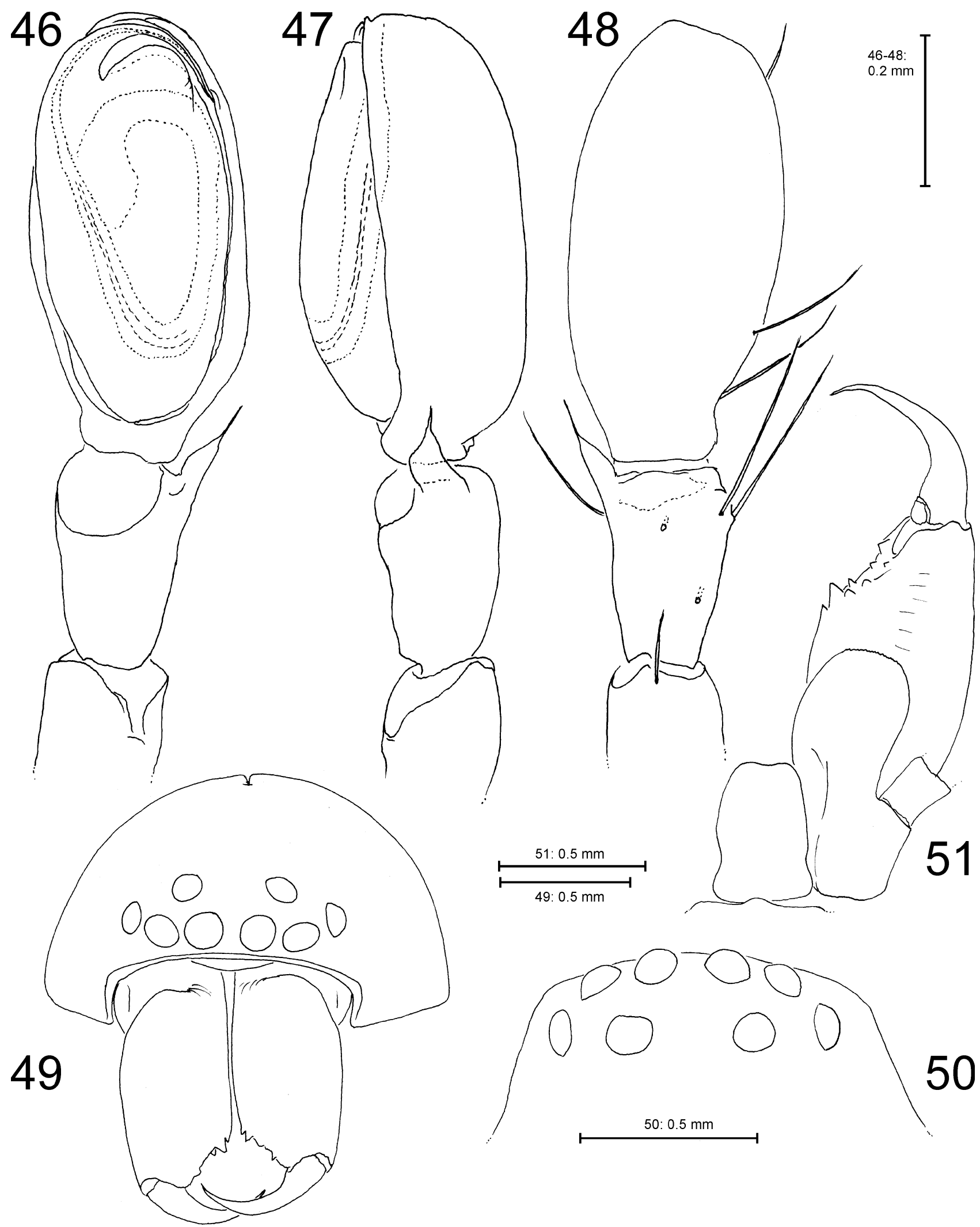

FIGURES 46-51. Clubiona kuu spec. nov., holotype male from Laos, Luang Prabang Province, Ban Keng Koung. 46-48 Left palp (46 ventral, 47 retrolateral, 48 dorsal). 49 Prosoma, frontal. 50 Eye arrangement, dorsal. 51 Labium, left chelicera and gnathocoxa, ventral. 
Colour in ethanol (Figs 57-59). Yellowish brown without colour pattern. Dorsal prosoma darker brown anteriorly, fovea distinct. Chelicerae, gnathocoxae and labium darker brown. Sternum marginally darker, with indistinct radial pattern. Appendages and opisthosoma pale yellowish brown. Dorsal opisthosoma with light brown patch above heart (resembling a scutum); ventral opisthosoma with light brown patch in front of epigastric furrow. Spinnerets slightly darker than opisthosoma.

Female: unknown.

Distribution. Known from Luang Prabang Province, Laos (Fig. 71: 4, 5).
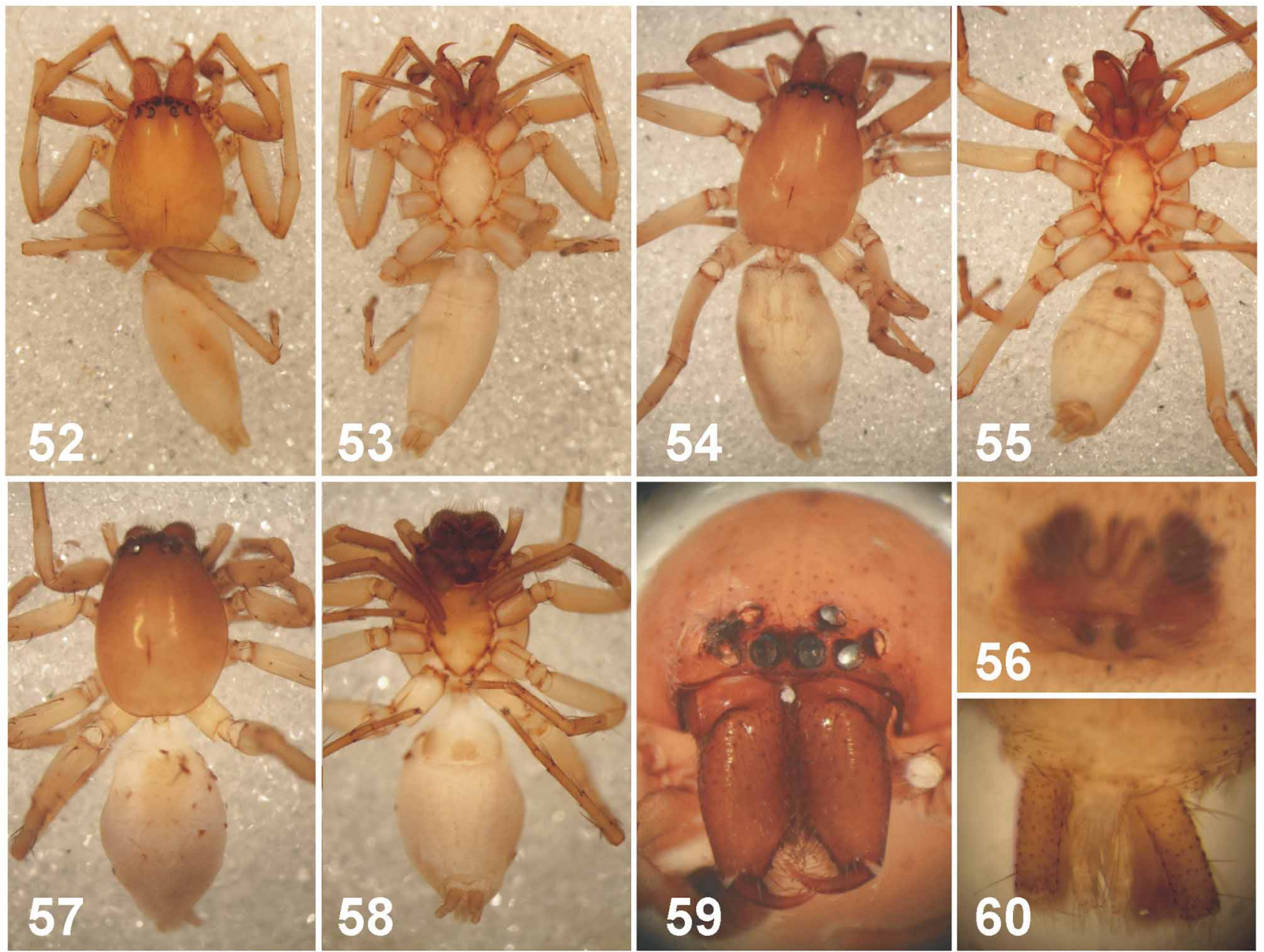

FIGURES 52-60. 52-56 Clubiona maipai spec. nov. from Thailand, Mae Hong Son Province, Ban Nam Rin (52-53 holotype male, 54-55 female paratype). 57-60 Clubiona kuu spec. nov., holotype male from Laos, Luang Prabang Province, Ban Keng Koung. 52-55, 57-59 Habitus (52, 54, 57 dorsal, 53, 55, 58 ventral, 59 frontal). 56 Epigyne, not cleared, ventral. 60 Spinnerets, ventral.

\section{Malamatidia Deeleman-Reinhold, 2001}

This genus was described for three species: the type species Malamatidia bohorokensis Deeleman-Reinhold, 2001 (Sumatra, Sarawak), M. vethi Deeleman-Reinhold, 2001 (Malaysian peninsular, Kalimantan), and M. thorelli Deeleman-Reinhold, 2001 (Sulawesi). The present specimens represent the first record of the genus for Laos. A single male from Luang Prabang Province and a single female from Luang Nam Tha Province are described as new species and represent the northernmost records for this genus. Both are considered separate species due to their different habitat (foliage vs. leaf litter), their different sizes (male with $6.5 \mathrm{~mm}$ vs. female with $4.5 \mathrm{~mm}$ body length; other Malamatidia spp. with both sexes of about the same size), and their different colours (grass-green in Fig. 73 vs. pale yellowish with distal leg segments bright brown in Fig. 74). Deeleman-Reinhold (personal communication) confirmed that most of small-sized Clubionidae occurring in natural forests are local endemics with small distribution ranges. According to the currently known distribution range the genus is likely to occur in neighbouring countries like China, Thailand, Myanmar, Vietnam and Cambodia. 
Diagnostic characters are according to Deeleman-Reinhold (2001) beside a pale green colour and a life style in the foliage, a longitudinal rim in the central depression of the female epigyne, and a filiform clockwise curving embolus (left palp) and an S-shaped loop of the sperm duct. From the two new species the diagnosis and description should be extended: Colour can be pale yellow with distal leg segments light brown, probably spiders live in the leaf litter (Fig. 74). It can be confirmed that metatarsi I and II have two long ventral spines. Moreover, the female exhibits 4 pairs of ventral tibial spines and — uniquely — one pair of ventral spines on patella I (Fig. 67)! An additional exceptional feature in $M$. christae spec. nov. is the female palpal tarsus with its roughly scalene triangle shape in lateral view with the shorter distal side being concave. The size range is extended up to $6.5 \mathrm{~mm}$ body length (previously known range: $3.75-5.3 \mathrm{~mm}$ ). Another diagnostic character for males could be the presence of a distinct and abrupt narrowing of the sperm duct in the tegulum (recognisable in M. bohorokensis, M. vethi and M. $z u$ spec. nov.; not clear in M. thorelli).

\section{Malamatidia $z$ u spec. nov.}

Figs 61-63, 71, 73

Type material: Holotype: male, LAOS: Luang Prabang Province: Ban Keng Koung, N $19^{\circ} 40.963^{\prime}$, E $102^{\circ}$ 18.442 ', $372 \mathrm{~m}$ altitude, in foliage, vegetation along stream, disturbed forest, by day, by sweeping, 24 February 2008, P. Jäger leg. (SMF, L15).

Etymology. The species name is derived from the German word "zu", meaning "too" and generally referring to an unbalanced situation as it is true for the overpopulation, i.e. too many people in a certain area. This is the case in the type locality Ban Keng Koung where people were settled because of building a dam at the Nam Khan; term in apposition.

Diagnosis. Males can be recognised by having the embolus tip situated at distal tegulum (retrolateral side in other Malamatidia spp.) and by the sperm duct with its broad part running straight distad, bent distally $180^{\circ}$, and with its narrow part running a loop before entering the embolus (Fig. 62).

Note. The prosoma of the holotype including legs (right pedipalp, leg I and II, and right leg III missing) and chelicerae is strongly damaged. Therefore no characters of these structures can be included in the diagnosis and description.

Description. Male (holotype; see note above). PL 2.4, PW 1.4, OL 4.0, OW 0.9. Eye diametres: ALE 0.11, PME 0.10, PLE 0.10. Eye interdistances: PME-PLE 0.09, ALE-PLE 0.07. Eye position similar to that of other Malamatidia spp., i.e. PME widely separated and ALE, PME and PLE appearing almost as triads (Deeleman-Reinhold 2001: figs 203-204, 209-210, 217). Leg and pedipalp measurements: pedipalp femur 0.69; leg I and II missing; leg III 4.99 (1.47, 0.58, 1.20, 1.23, 0.51); leg IV 7.63 (2.18, 0.72, 1.95, 2.12, 0.66). Spination: Pedipalp femur: 131; Femur III d111, r010, IV d111; Patella III-IV r010; Tibia III p010, d101, r110, v110, IV p011, d101,r011, v110; Metatarsus III p001, d212, r001, v202, IV p001, d233, r001, v211.

Prosoma, opisthosoma including spinnerets and anal tubercle elongated as in M. bohorokensis (DeelemanReinhold 2001: figs 203-204). Palp with cymbium distinctly longer than tibia. Distal RTA sub-rectangular. Embolus arising from centre of tegulum, sickle-shaped. Prolatero-basal membranous part (=subtegulum/hematodocha?) extending into distal half of tegulum (Figs 61-63). Sperm duct with distinct and abrupt narrowing in distal half of tegulum. Other palpal structures as in diagnosis.

Colour in ethanol. Pale yellow, dorsal prosoma and chelicerae a bit darker. Dorsal opisthosoma with greyish median band with distinct lateral margins in posterior half. Ventral opisthosoma with distinct dark patch in front of epigastric furrow.

Colour of a living subadult male was bright green (Fig. 73; the same colour was exhibited by an unidentified individual from Champasak Prov., That Fane, L95).

Female: unknown.

Natural history. The holotype of $M . z u$ spec. nov. has been collected from foliage in vegetation close to a small stream. This is in accordance with data provided by Deeleman-Reinhold (2001: 191, "Silk-sheets on the under-surface of green leaves") and with other records of Malamatidia spiders in Laos (Champasak Prov.).

Distribution. Known only from the type locality (Fig. 71: 5). 


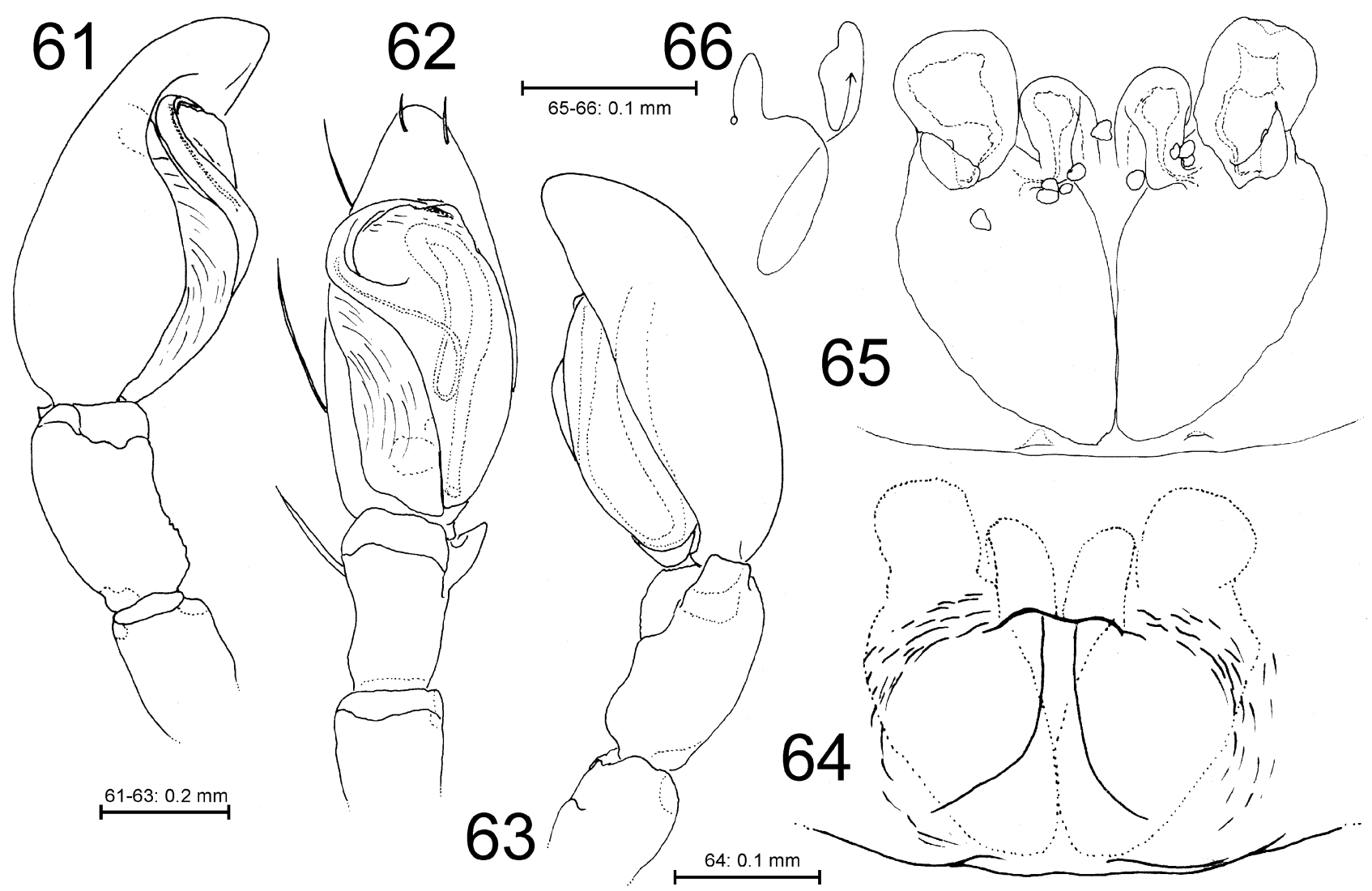

FIGURES 61-66. 61-63 Malamatidia zu spec. nov., holotype male from Laos, Luang Prabang Province, Ban Keng Koung. 64-65 Malamatidia christae spec. nov., holotype female from Laos, Luang Nam Tha Province, Vieng Phou Kha. 61-63 Left palp (61 prolateral, 62 ventral, 63 retrolateral). 64 Epigyne, ventral. 65 Vulva, dorsal. 66 Schematic course of internal duct system, dorsal.

\section{Malamatidia christae spec. nov.}

Figs 64-71, 74

Type material. Holotype: female, LAOS: Luang Nam Tha Province: Vieng Phou Kha, Phou Pasat, Tham Pasat Thia, outside cave, forest, leaf litter, by day, sieving, 4 March 2008, P. Jäger leg. (SMF, L44).

Etymology. The species is named in honour of Dr Christa Deeleman-Reinhold for her invaluable contribution to the knowledge of the Southeast Asian spider fauna; name in genitive case.

Diagnosis. The longitudinal, posteriorly diverging rim in the central depression of epigyne is diagnostic for Malamatidia spp. (Deeleman-Reinhold 2001: 191). The female of M. christae spec. nov. is distinguished by the large and posteriorly pointed membranous posterior parts of the spermathecae (Fig. 65) (round and smaller in other Malamatidia spp.).

Description. Female (holotype). PL 1.8, PW 1.2, OL 2.7, OW 0.9. Eye diametres: AME 0.065, ALE 0.10, PME 0.07, PLE 0.09. Eye interdistances: AME-AME 0.05, AME-ALE 0.35, PME-PME 0.19, PME-PLE 0.08, AME-PME 0.09, ALE-PLE 0.055, clypeus AME 0.03, clypeus ALE 0.03. Leg and pedipalp measurements: pedipalp 1.56 (0.50, 0.23, 0.36, -, 0.47); leg I 4.80 (1.34, 0.62, 1.42, 0.90, 0.52); leg II 5.64 (1.60, 0.71, 1.68, 1.05, $0.60)$; leg III 4.10 (1.19, 0.50, 0.96, 1.01, 0.44); leg IV 6.35 (1.75, 0.63, 1.62, 1.76, 0.59). Leg formula. 4213. Spination: Pedipalp femur: 130, patella 000, tibia 2012, tarsus 10(1)13; Femur I-IV d001; Patella I v020; Tibia I 22220, II v20200, III p010, r010, v110, IV p011, r011, v110; Metatarsus I-II v200, III p001, d212, r001, v202, IV p111, d012, r111, v213. Metatarsal ventral spines I-II long (I 0.66). Chelicerae length 0.6, with 3 anterior and 2 posterior teeth. Prosoma, opisthosoma including spinnerets and anal tubercle elongated as in M. bohorokensis (Deeleman-Reinhold 2001: fig. 204). 
Copulatory organ as in diagnosis. Epigynal field dark grey, round (Fig. 70). Epigyne with transversal rim distinct, short and slightly undulated. Copulatory ducts short and running in a semicircle into the large membranous posterior parts of the internal duct system. Sclerotised anterior parts spherical and with thick walls. No glandular pores recognisable. Fertilisation duct short and dorsad.

Colour in ethanol. Prosoma and opisthosoma pale yellow with spinnerets and labium light grey and distal leg segments darker (Figs 67-69). Screw-coiled spinning glands visible in ventral view (Fig. 68). Colour of the living holotype female was bright yellow with darker distal leg segments (Fig. 74).

Male: unknown.

Natural history. The holotype of M. christae spec. nov. has been collected by sieving leaf litter in a patch of seemingly primary forest.

Distribution. Known only from the type locality (Fig. 71: 2).
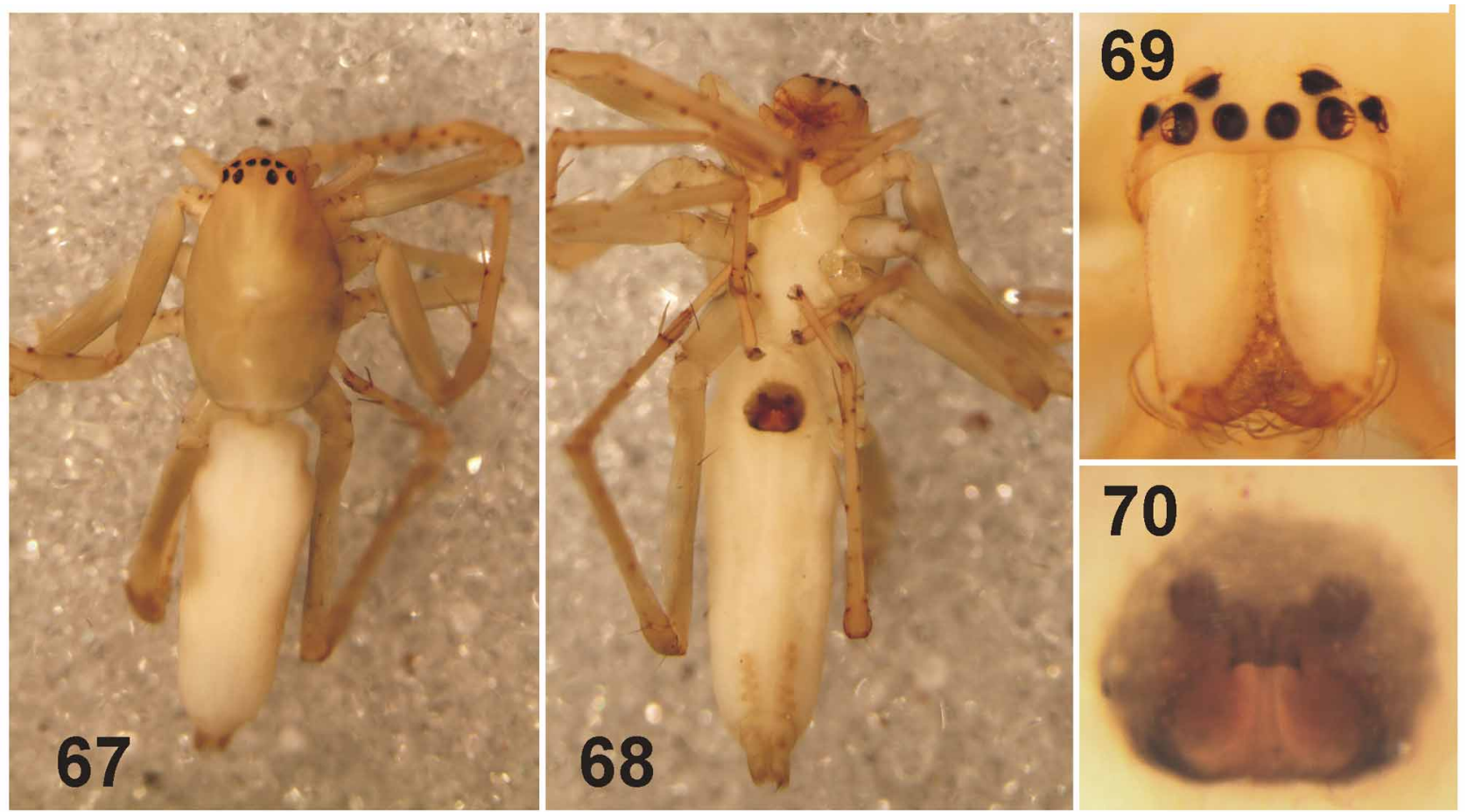

FIGURES 67-70. Malamatidia christae spec. nov., holotype female from Laos, Luang Nam Tha Province, Vieng Phou Kha. 67-69 Habitus (67 dorsal, 68 ventral, 69 frontal). 70 Epigyne, not cleared, ventral.

\section{Pristidia viridissima Deeleman-Reinhold, 2001}

Fig. 71

Material examined. Thailand: Trat Province: 1 female, Gulf of Thailand, north side of Ko Chang, Khlong Chao Luam, $\mathrm{N} 12^{\circ} 6.503$ ', E $102^{\circ} 18.015 ', 30-150 \mathrm{~m}$ altitude, secondary forest, along stream, vegetation, at day, by hand, 3 November 2009, P. Jäger \& S. Bayer leg. (SMF 60456).

With $4.1 \mathrm{~mm}$ body length this female falls into the size range given by Deeleman-Reinhold (2001: 3.5-5.5 $\mathrm{mm})$. PME-PME is slightly less than two diameters PME and, thus, also in accordance with the range of variability given in the original description.

Distribution. Thailand to Borneo (Deeleman-Reinhold 2001) (Fig. 71: 13). 


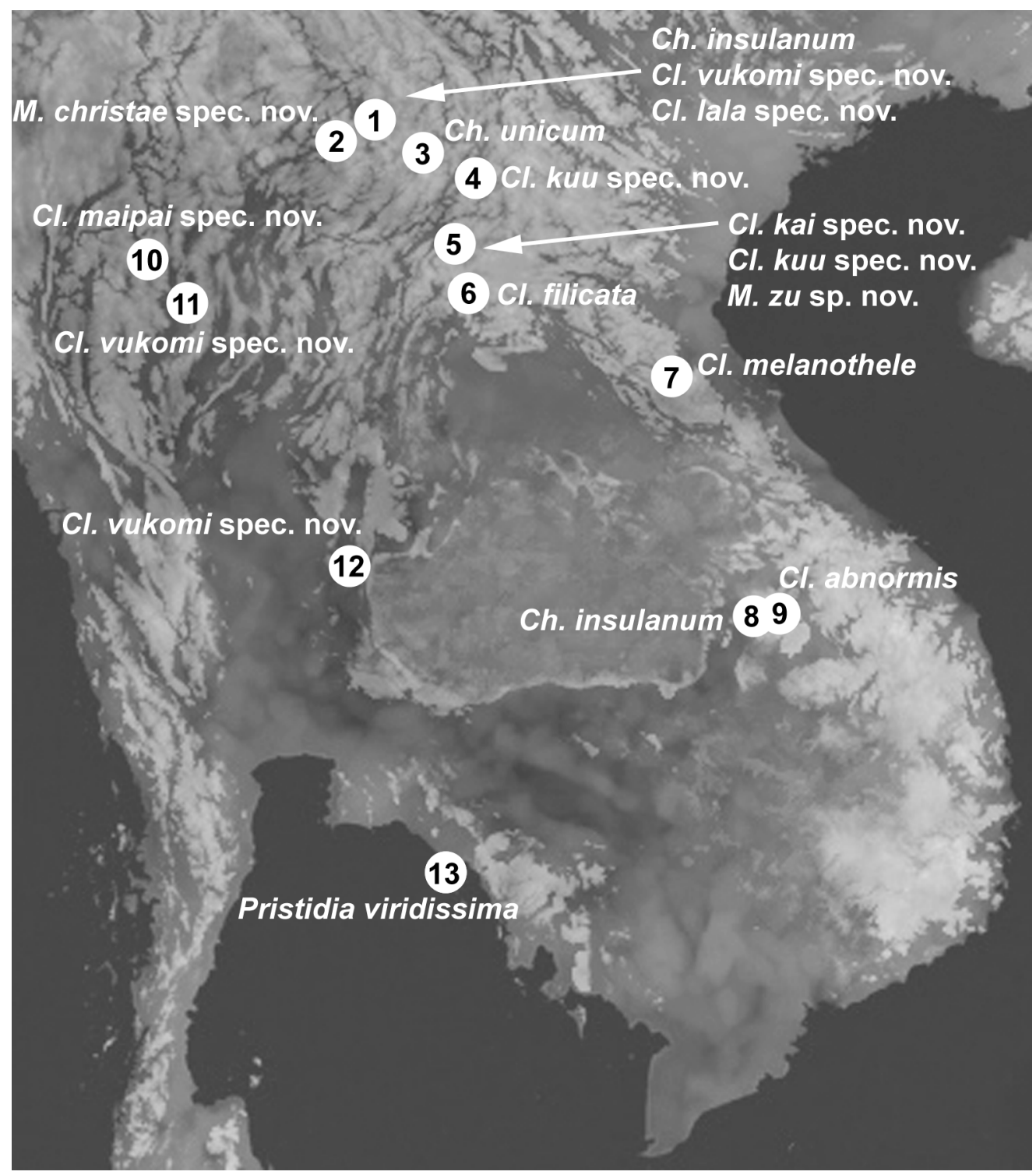

FIGURE 71. Localities of Clubionidae treated in this paper in Laos (1-9) and Thailand (10-13). 1-2 Luang Nam Tha Province (1 2-6 km N of Luang Nam Tha, 2 Vieng Phou Kha). 3 Oudomxai Province, Oudomxai. 4-5 Luang Prabang Province (4 Nong Khiao, 5 Ban Keng Koung). 6 Vientiane Province, Vang Vieng, Ban Phoxay. 7 Bolikhamsay Province, Lak Sao. 8-9 Champasak Province (8 Pakse, Ban Ke; 9 That Fane). 10 Mae Hong Son Province, Ban Nam Rin. 11 Chiang Mai Province, Chiang Mai. 12 Chai Ya Phum Province, Pa Hin Ngam National Park. 13 Trat Province, Ko Chang.

\section{Acknowledgements}

Peter Jäger is grateful to Prof. Dr Bounthob Praxaysombath (National University of Laos, Vientiane), the director Chanthavong Phonnachit and the volunteers Arnaud Vontobel and Antoine Borius from the Water Resources Environment Administration (WREA), Luang Prabang for their various help in the organisation of the field work and for supporting Peter Jäger's work within the partnership between the Research Institute Senckenberg and the Nam Khan eco-valley prefiguration study (candidate for The UNESCO Man and the biosphere program) hosted at the WREA in Luang Prabang. Thanks to Jürgen Hinderlich and Robby Dehondt (both latter Solidaritätsdienst International e.V., Lak Sao, Laos), Gerry Duckit and Ian Baird (both latter Global Association for People and Environment, Pakse, Laos) for support and logistics in the field in Laos. Damir Kovac (SMF) collected material in Thailand, and Dinendra Raychaudhuri (Calcutta) sent literature. Christa Deeleman-Reinhold (Ossendrecht) provided additional information on the biology and taxonomy of Clubioninae species. We thank all persons and institutions for their support. 


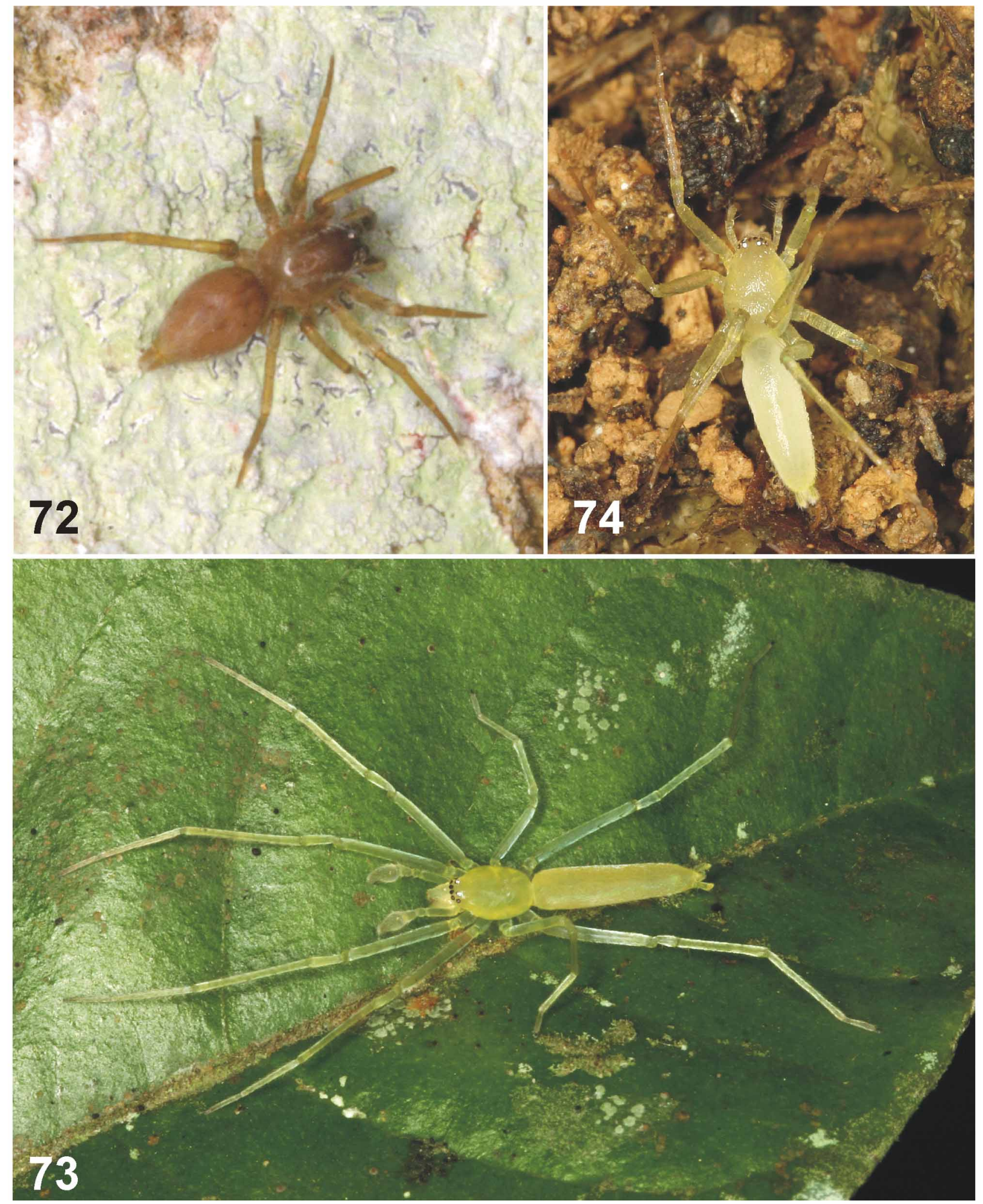

FIGURES 72-74. 72 Clubiona kuи spec. nov., holotype male from Laos, Luang Prabang Province, Ban Keng Koung, in original habitat at the type locality. 73 Malamatidia zu spec. nov., subadult male from Laos, Luang Prabang Province, Ban Keng Koung, in original habitat at the type locality. 74 Malamatidia christae spec. nov., holotype female from Laos, Luang Nam Tha Province, Vieng Phou Kha, in origianl habitat at the type locality. 


\section{References}

Barrion, A.T. \& Litsinger, J.A. (1995) Riceland Spiders of South and Southeast Asia. CAB International, Wallingford, UK, xix $+700 \mathrm{pp}$

Biswas, V. \& Raychaudhuri, D. (1996) Clubionid spiders of Bangladesh - I: Genus Clubiona Latreille. Proceeding of recent Advances in Life Sciences (1994), Dibrugarh Univ, 1, 191-210.

Carr, J. \& Langhammer, P. (2010) Biodiversity hotspots. Conservation International. Available from: http://www.biodiversityhotspots.org/xp/hotspots/Pages/default.aspx (accessed 18 October 2010).

Chen, S.-H. \& Huang, W.-J. (2004) A newly recorded spider of the genus Cheiracanthium (Araneae, Clubionidae) from Taiwan. BioFormosa, 39, 55-59.

Chrysanthus, P. (1967) Spiders from south New Guinea VIII. Nova Guinea (N.S., Zool.), 37, 401-426.

Dankittipakul, P. \& Singtripop, T. (2008a) Five new species of the spider genus Clubiona Latreille (Araneae: Clubionidae) from Thailand. Zootaxa, 1747, 34-60.

Dankittipakul, P. \& Singtripop, T. (2008b) Spiders of the Clubiona corticalis group from Thailand, with descriptions of three new species (Araneae: Clubionidae). Zoological Studies, 47, 644-656.

Deeleman-Reinhold, C.L. (2001) Forest spiders of South East Asia: with a revision of the sac and ground spiders (Araneae: Clubionidae, Corinnidae, Liocranidae, Gnaphosidae, Prodidomidae and Trochanterriidae). Brill, Leiden, 591 pp.

Gravely, F. H. (1931) Some Indian spiders of the families Ctenidae, Sparassidae, Selenopidae and Clubionidae. Records of the Indian Museum, Calcutta, 33, 211-282.

Jäger, P. (2007) Spiders (Araneae) from Laos with descriptions of new species. Acta Arachnologica, 56, $29-58$.

Jäger, P. \& Praxaysombath, B. (2009) Spiders from Laos: new species and new records (Arachnida: Araneae). Acta Arachnologica, 58, 27-51.

Mikhailov, K.G. (1995) Erection of infrageneric groupings within the spider genus Clubiona Latreille, 1804 (Aranei Clubionidae): a typological approach. Arthropoda Selecta, 4, 33-48.

Murphy, F. \& Murphy, J. (2000) An introduction to the spiders of South East Asia with notes on all the genera. Malaysian Nature Society, Kuala Lumpur, 625 pp. +32 pl.

Ono, H. (2009) Three new spiders of the family Clubionidae, Liocranidae and Gnaphosidae (Arachnida, Araneae) from Vietnam. Bulletin of the national Museum of natural Science Tokyo (A), 35, 1-8.

Ono, H. \& Hayashi, T. (2009) Clubionidae. In: Ono, H. (ed.), The Spiders of Japan with keys to the families and genera and illustrations of the species. Tokai Univ. Press, Kanagawa, pp. 532-546.

Platnick, N.I. (2010) The world spider catalog, version 11.0. American Museum of Natural History. Available from: http:// research.amnh.org/iz/spiders/catalog/INTRO1.html (accessed 18 October 2010).

Raven, R.J. (2009) Revisions of Australian ground-hunting spiders: IV. The spider subfamily Diaprograptinae subfam. nov. (Araneomorphae: Miturgidae). Zootaxa, 2035, 1-40.

Zhang, Y.-J. \& Yin, C.-M. (1998) Six new species of the spiders of genus Clubiona from China (Araneae: Clubionidae). Acta zootaxononomica sinica, 23, 9-17.

Zhang, Y.-J. \& Yin, C.-M. (1999) Two new species of the genus Cheiracanthium from China with notes on male spiders of two species (Araneae: Clubionidae). Acta zootaxonomica sinica, 24, 285-290. 